\title{
Visual Comfort Analysis of Innovative Interior and Exterior Shading Systems for Commercial Buildings using High Resolution Luminance Images
}

Kyle Konis Eawrence Berkeley Nabional Laboratory

Eleanor Lee Lawrence Berkeley National Labortory

Robert Clear Lawrence Berkeley National Laboratory

January 2011 


\section{DISCLAIMER}

This document was prepared as an account of work sponsored by the Uniled States Government. While this document is believed to contain correct information, neither the United States Government nor any agency thereof, nor The Regents of the University of California, nor any of their employees, makes any wartanty, express or implied, or assumes any legal responsibility for the accuracy, completeness, or usefultess of any information, apparatus, product, or process disclosed, or represents that its use would not infringe privately owned rights. Reference herein to any specific commercial product, process, or service by its trade name, trademark, manufacturer, or otherwise, does not necessarily constitute or imply its endorsement, recommendation, or favoring by the United States Government or any agency thereof, or The Regents of the University of California. The views and opinions of authors expressed herein do not necessarily state or reflect those of the United States Govemment or any agency thereof or The Regents of the University of California. 


\title{
Visual Comfort Analysis of Innovative Interior and Exterior Shading Systems for Commercial Buildings using High Resolution Luminance Images
}

\author{
K.Konis, E.S.Lee, R.D.Clear, Ph.D \\ Building Technologies Prograw, Environmental Energy Technologies Division, Lawrence Berkeley \\ Nationat Laboratory, Maitstop 90-31/1, Cyclotron Road, Berketey, CA 94720, USA
}

\begin{abstract}
The objective of this study was to explore how calibrated high dynamic range (HDR) images (luminance maps] acquired in real world daylit environments can be used to characterize, evaluate, and compare visual comfort conditions of innovative facade shading and light-redisecting systems. Delailod (1536 x 1536 pixel) luminance maps werc timc-lapse acquired from two view positions in an unoccupiod full scale tesibed facility. These maps were analyzed using existing visual comtort metries to quantify how innovative interior and exterior shading systems compare to conventional systems under real sun and sky conditions over a solstice-to-golstice test interval. The results provide a case study in the challenges and potential of methods of visualizing, evaluating and summatizing daily and seasonal variation of visual comfort conditions compuled from large sets of image data.
\end{abstract}

Keswords: daylighting, high dynamic range imaging, discomfort glare.

\section{Intreduction}

In recent years, mainstream acceptance of the "green building movement" has led to the construction of a significant number of buildings with highly glazed facades, designed with the dual goals of 1 ) complying with green building certification programs (e.g., LEED daylight and vicw credits) and 2) the teduction of electrical lighting energy consumption via daylighting. Casual inspection of these buildings in operation often reveals that shading syslems are routinely deployed by oceupants to maintain comfortable visual conditions, reducing the potential for lighting energy reduction as well as visual connection to the exteripr.

This study focuses on evaluating the visual confort conditions produced from a number of innovative interior and exterior facade shading and light-redirecting systems that have the potenlial to more effectively balance the goals of visual comfort with daylight transmission in comparison to conventional shading systems (e.g. manually operated Venetian blinds or roller shades) used in typical sidelit perimeter zones. In this sludy, the term "innovative" refers to systens that employ one or more of the following stralegies; sub-division of the window wall into an upper daylighting zone and a lower "view" zone, optical light redirection, translucent materials, and automation of slat angle and/or height adjustment.

Prior to the availabjlity of luminance maps to assess lighting conditions in real spaces, the limitations of available photonetric monitoring equipment (e.g., shielded illuminance sensors, spot luminance meters) resulted in simplified methods of glare assessment in daylit spaces. Ayerage luminances of large window areas using shielded sensors have commonly been used to compute the daylight glare index (DGI) [IEA SHC 
Task 21, 2000] as well as numerous other discomcort glare indices. In addition, average luminances from shielded sensors have been correlated to subjective response data in the derivation of a predictive model that relates the average luminance of the entire window to the plobability of the shade being lowered [Clear et a]. 2006].

The primary limitation of these methods is that the boundary of the glare source must be pre-defined. This is a problem in daylit spaces because the boundary and position of glare sources are constattly changing. An additional limilation is that a physical shield must be fabricated with a profile identical to the desired target. This presents a challenge when defining largets with itregular profiles, such as the boundary belween the landscape and the sky as viewed through the window. A final limitation is that each pre-defined region requires an individual illuminance sensor, restricting the number of glare sources that can be defined for practical reasons, often leading to the entire wishow being defitted as a single (and very large) glare source. Because the DGI is sensitive to both the size and position of each glare source, the definition of the entire wintow as a single source can lead to misleading results.

IIDR inages store luminance data oln a "per-pixel" scale, providing far greater resolution for visual comfort analysis, enabling both the definition and analysis of an arbitrary number of pre-defined regions, and the possibility of detecting glare sources throughout the full field of view to compute any number of discomfort glare metrics. In computer graphics, the original HDR format (Radiance RGBE) was developed for the lighting sirnulation engine Radiance in order to record the photometric conditions of synthetic lighting environments [Ward 1991, 1994]. In following yoars, techniques were developed to produce HDR images from real-world scenes [Debevec 1997, Mitsunaga \& Nayar 1999] by composiling truitiple, exposurebracketed, low dynamic range ( $C, D R$ ) images (e.g.. JPEO) into a single HDR image. Motivated by the possibility of using HDR in real spaces for photomeltic analysis, methods are now available to produce calibrated HDR images, comimonly referred to as luminance maps [Inanici \& Galvin. 2004]. Wienold and Christoffersen [2006] derived a new daylight glare prediction model based on HDR data correlated to subjective responss.

In this sludy, two methods of visual comfort analysis using luminance maps are demonstratod on a variety of interior and cxtcrior shading systems, some with reflective surfaces, some with automatco controls, and some where the window wall is subdivided into an upper and lower region. These systems have been designed to more effectively balance the compeling goals of adnitting useful daylight without the associated glarte. The Ifluminating Engineering Society of North America (IESNA) recommended contrast ratio limits and Hopkinson Cornell I, arge Source Glare Index (UGI)' are used as a basis for evaluation. The analysis focuses on addressing two questions: Do existing metrics and summary indices computed from Iuminance maps enable differentiation between systems? And, what value can time-lapse imaging add over more conventional methods of visual comfort assessment?

\section{Measurenents and procedures}

\section{I. Test focility}

Experimental tests were conducted in the $88.4 \mathrm{~m}^{2}\left(952 \mathrm{ft}^{2}\right)$ Advanced Windows Testbed Facility located at the Lawrence Berkeley National Laboralory (LBNL) in Berkeley, California (latitude $37^{\circ} 4 \mathrm{~N} N$, longilude $122^{\circ} \mid{ }^{\prime} W$ ). The facility consists of three identical side-by-side test rooms (Figure I) built to represent a commercial office envifonment and were unoccupied during this study. Testing was condocted with electric lighting on and dimmed to maintain a setpoint illuminance of 538 lux at the workplane.

\footnotetext{
' We did nol use the Wienold and Christoffersen's glare prediction model due to an error in the software lool at the time, which prevented analysis of our HDR images.
} 

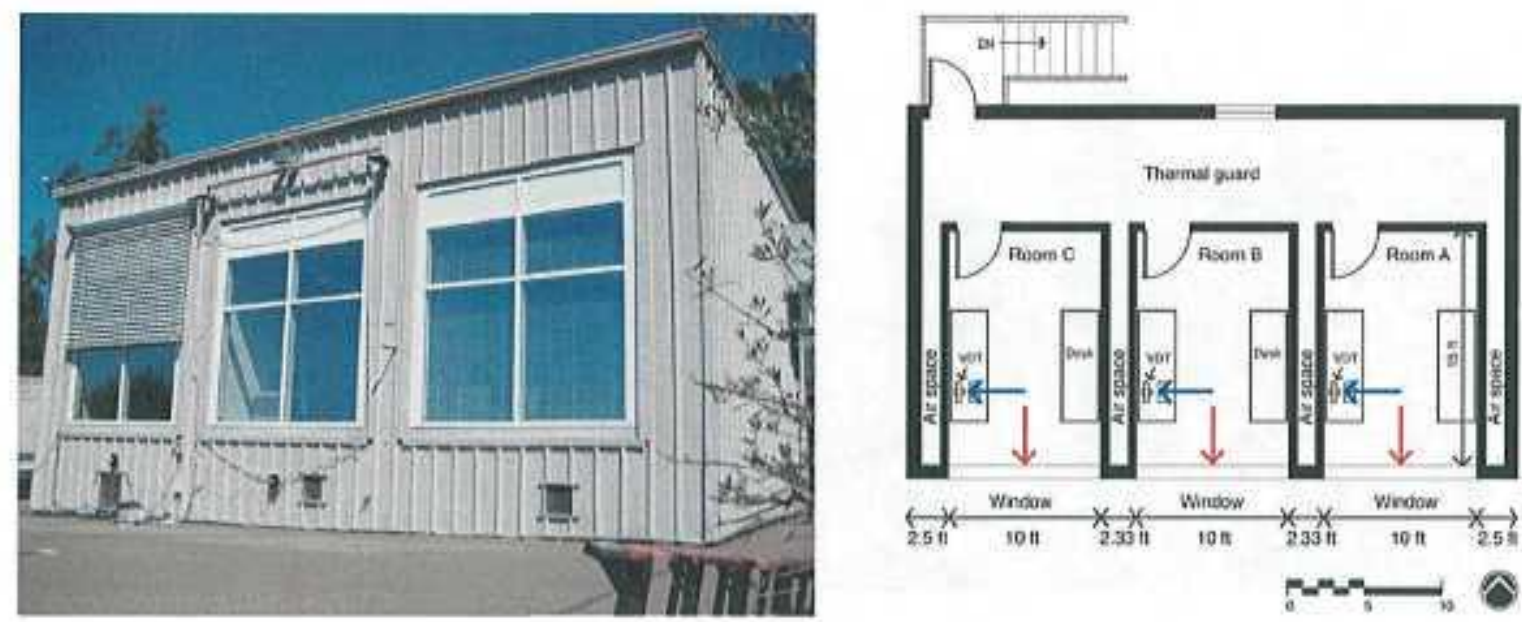

Figure 1. Exterior view of the south-facing facade of the Advanced Windows Testbed Facility (left) and floor plan indicating view positions of HDR measurements in each test room (right).

\subsection{Acquisition of HDR Images}

Images were taken vertically at two locations within each room assuming a seated occupant $(1.2 \mathrm{~m}(4 \mathrm{ft})$ eye height): a) looking at the west sidewall and computer monitor or visual display terminal (VDT) $1.52 \mathrm{~m}(5 \mathrm{ft})$ from the window and b) normal and centered on the window, $1.2 \mathrm{~m} \mathrm{(4ft)}$ from the window (Figure 1). Images were acquired from $6 \mathrm{AM}$ to 6 PM Standard Time and therefore some data include non-daylit conditions.

Each HDR image was composited from a set of nine, $1536 \times 1536$ pixel, LDR images, exposure-bracketed in 1 EV steps using conventional CCD cameras (Nikon 990) with an equidistant fisheye lens (Nikon fc e8, $183^{\circ}$ ). Compositing was achieved using the program hdrgen, which converts the RGB pixel values of exposure bracketed LDR images into real-world luminances [Mitsunaga \& Nayar 1999]. Automation of acquisition and exposure bracketing was achieved using a series of scripts written for this application. A more general script (HDRcapOSX) was written later for the higher quality Canon EOS 5D digital camera series for a related project, which was then ported and tested on the Mac OS X 10.5.8 operating system by [Fan and Mardaljevic 2009]. This script is backwards compatible to OSX 10,4.x and available free at: (http://www.iesd.dmu.ac.uk/-jm/doku.php?id=resources:hdreaposx).

\subsection{Post-processing of HDR images}

To correct for the light fall off typical of wide-angle camera systems, a "digital filter" was applied to each HDR image as a post-process in Radiance using the method developed by Inanici \& Galvin [2004]. During the time required to acquire a bracketed set of images ( $\sim$ minute), the luminous environment is rarely stable and large swings in outdoor sky conditions can introduce significant measurement errors. To control for unstable lighting conditions, the global vertical illuminance computed from the image was compared to the average of two readings from an adjacent vertical illuminance sensor (type $=$ Licor $\mathrm{LI}-210$, cosine-corrected, nominal accuracy $=3 \%$, range $=0-15,000$ lux $)$ : immediately before and after acquisition of the bracketed set of images (Figure 3). The image was then uniformly scaled by adjusting the exposure line of the image file header so that the global vertical illuminance computed from the image matched the average of the two illuminance readings. 

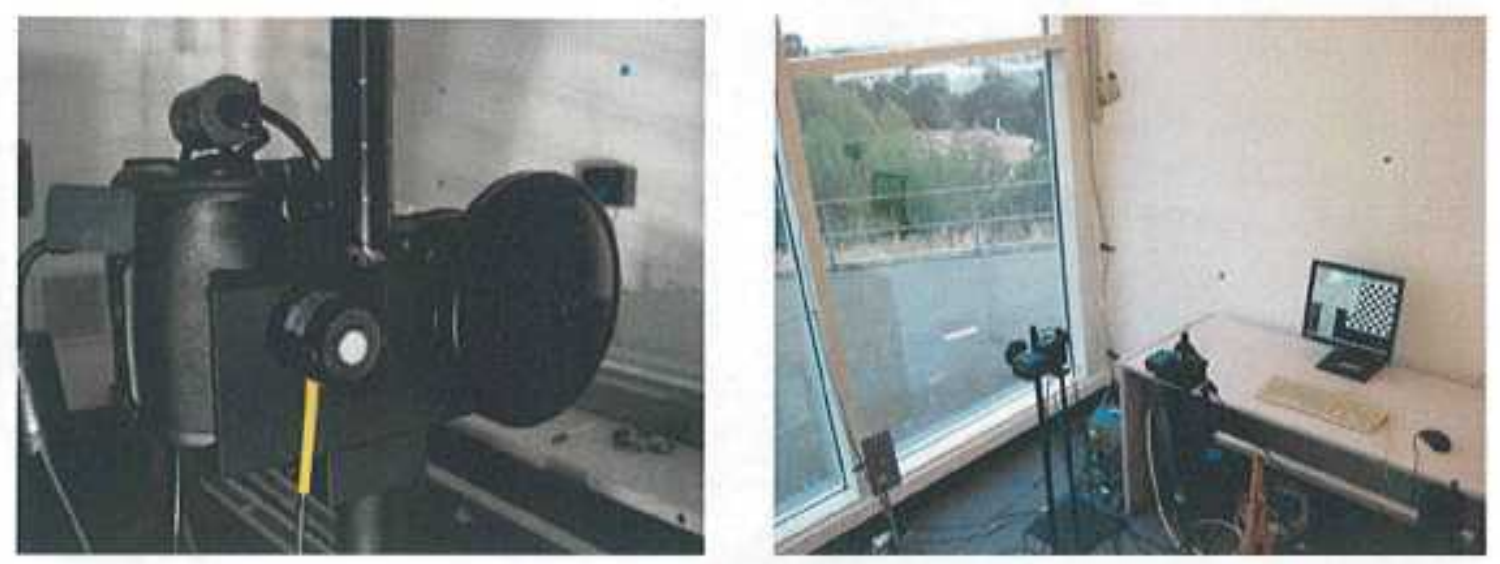

Figure 3. Image of typical Nikon 990 camera setup with the adjacent vertical illuminance sensor used in calibration of HDR luminance maps (left) and overview of position and orientation of cameras in a test room (right).

\subsection{Measurement Errors}

To quantify errors associated with changes in vertical illuminance during acquisition, a test was performed to examine the accuracy of luminance maps under dynamic sky conditions. The camera was positioned adjacent to a shielded luminance sensor. A mask was defined for the luminance maps that matched the field of view of the shielded sensor (Figure 5). The average luminance computed from the luminance map was then compared to the shielded sensor and reported in terms of percent error and magnitude error. Figure 7 presents data for one of the six cameras tested. Each of the six cameras was tested for one day resulting in a total of $\sim 144$ images per camera ( 867 images total). During this test, the average luminance of the masked region ranged from 0 to $11,990 \mathrm{~cd} / \mathrm{m}^{2}$ (average of all observations $=2997 \mathrm{~cd} / \mathrm{m}^{2}$, std.dev $=3011 \mathrm{~cd} / \mathrm{m}^{2}$ ), and the global vertical illuminance at the lens ranged from 0 to 11,900 lux.

Results (presented in Figure 9 and Table 1) show that measurement accuracy was affected by both the magnitude of the change in global vertical illuminance during acquisition (Figure 9) and when the global vertical illuminance at the lens was very low $(<50$ lux $)$. When the global vertical illuminance at the lens was above 50 lux, the average error of the six cameras combined was $0.21 \%$, with a standard deviation of $7.6 \%$. Within this set of data, accuracy was shown to decrease when the change in global vertical illuminance during acquisition exceeded $5 \%$ (avg. error $=5.46 \%$ std. error $=13.59 \%$ ), compared to when the change was less than $5 \%$ (avg. error $=-0.21 \%$ std. error $=5.79 \%$ ). When the global vertical illuminance at the lens was less than 50 lux ( $N=67$ images), the percent error of all cameras was significantly larger, however the magnitude error was not significant (avg. magnitude error $=8 \mathrm{~cd} / \mathrm{m}^{2}$, $\max$ magnitude error $=20 \mathrm{~cd} / \mathrm{m}^{2}$ ). Because this study focused on glare analysis, the small magnitude errors introduced by images acquired at global vertical illuminance levels below 50 lux were not considered a problem, and therefore images acquired under these conditions were retained. 

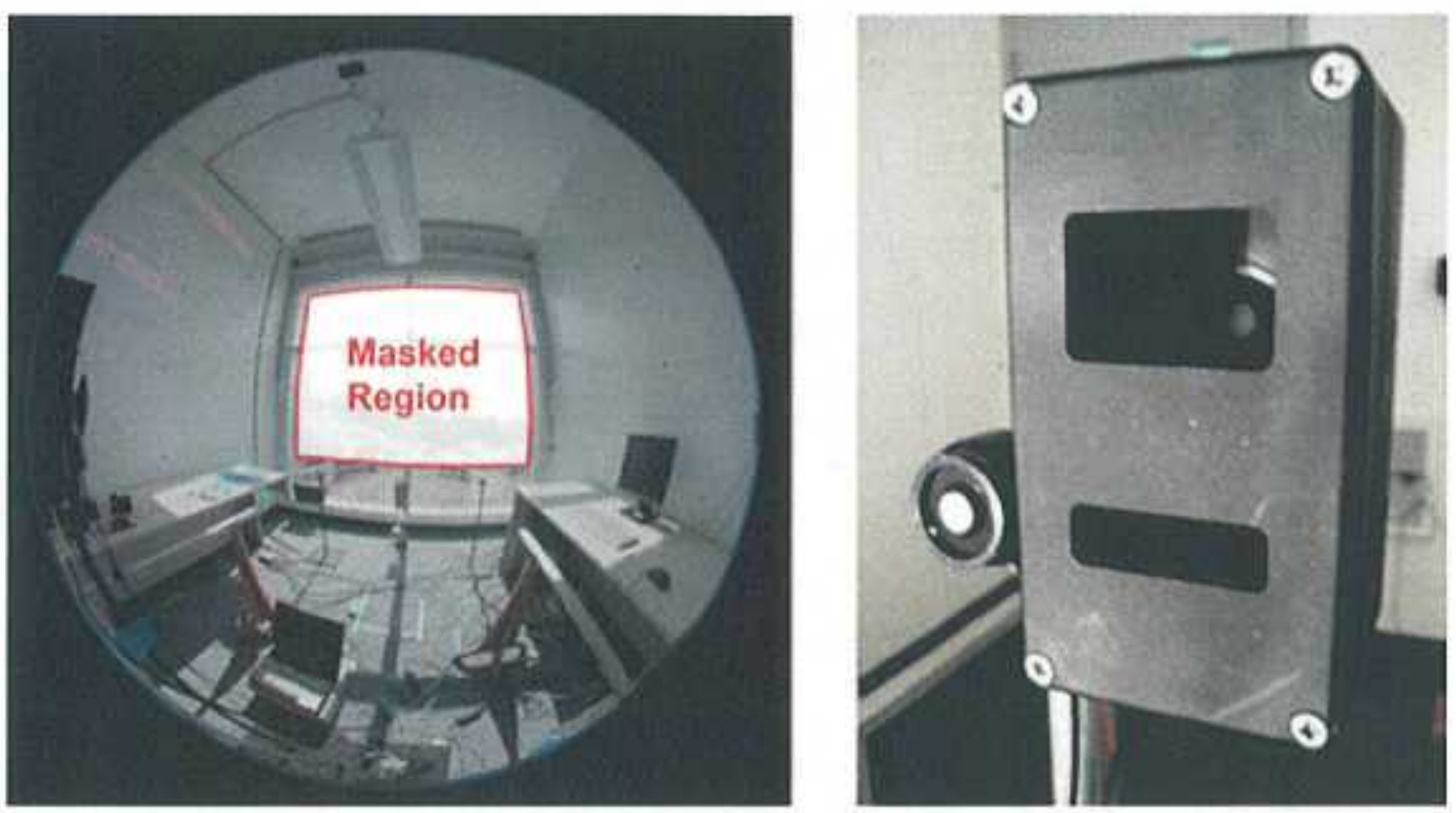

Figure 5. Illustration of the masked window region (left) that was compared to the equivalent region monitored by the shielded illuminance sensor (right). 


\section{HDR vs. Shielded Illuminance Sensor (Lux9) for B.WIN Camera}
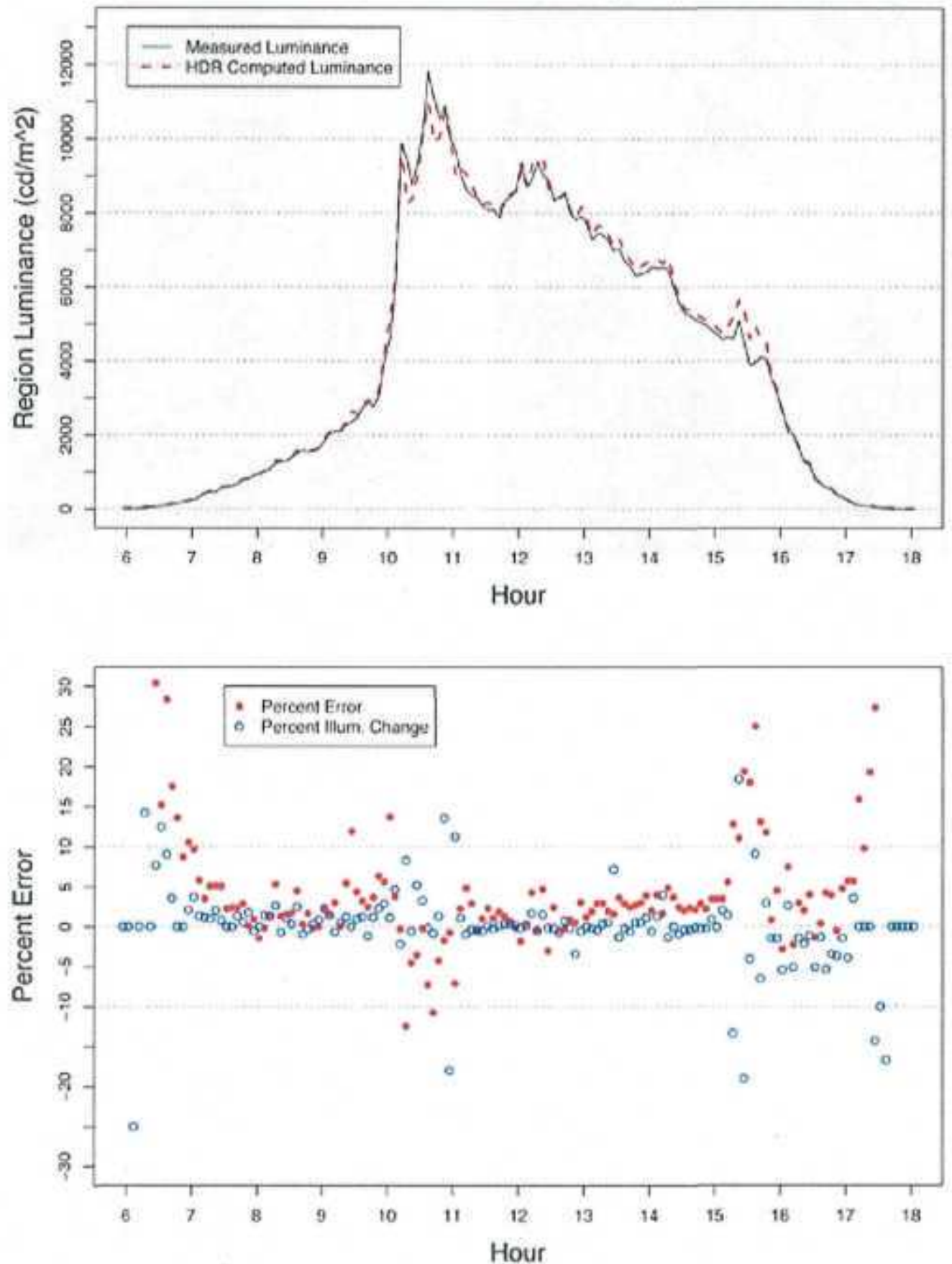

Figure 7. Comparison of window-region luminance derived from luminance maps versus a shielded illuminance sensor under dynamic sky conditions. Errors in excess of $30 \%$ occurred during low ambient lighting conditions and are not shown in the lower figure. All errors are summarized in Table 1. 


\section{Measurement errors associated with change in vertical illuminance during acquisition}

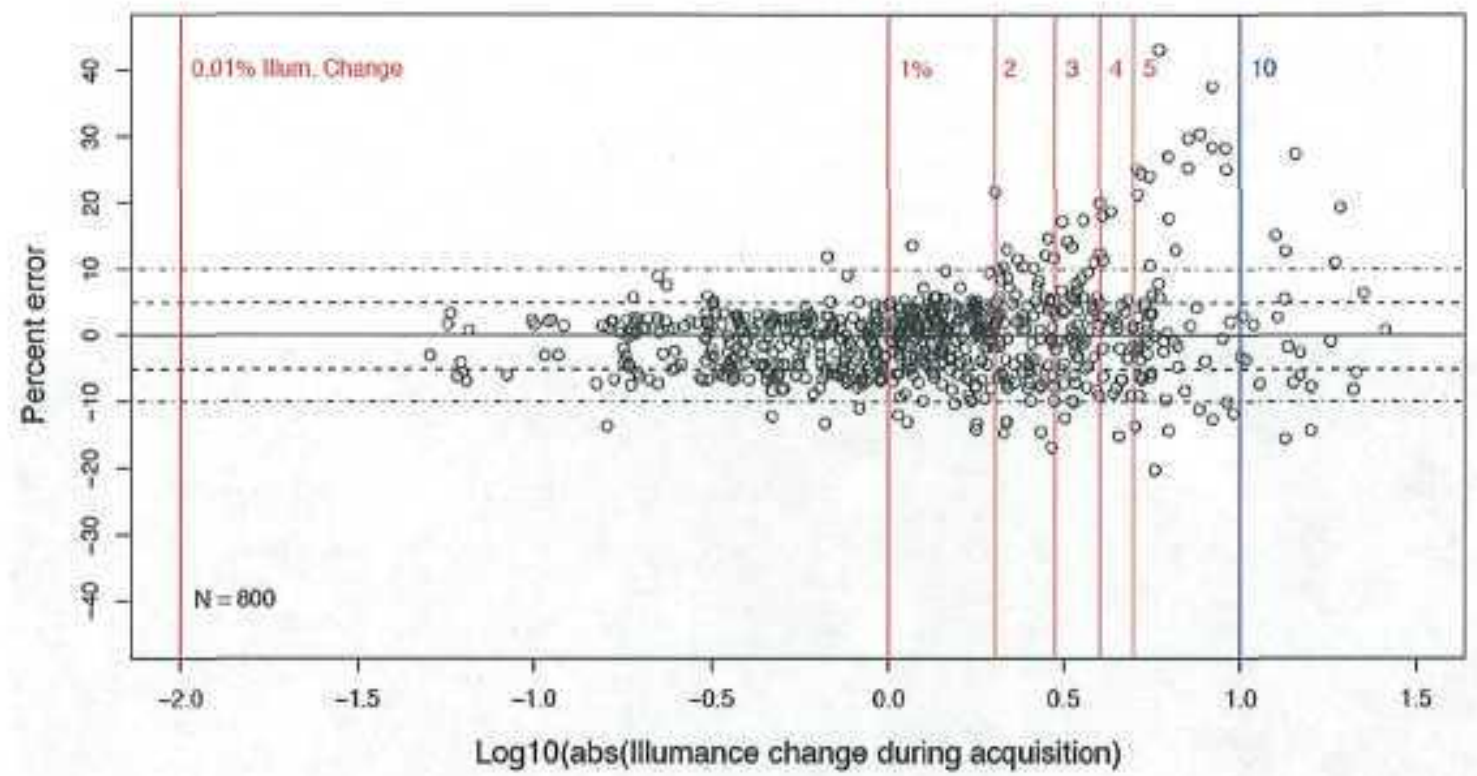

Figure 9. Illustration of the increasing magnitude of measurement errors as sky conditions (represented by change in vertical illuminance during acquisition) become increasingly unstable. This figure includes one day of image data ( 6 AM to $6 \mathrm{PM}$ ) for each of six cameras and does not include data acquired under low light levels (vertical illuminance $<50$ lux).

Table 1. Measurement Errors During Unstable Sky Conditions.

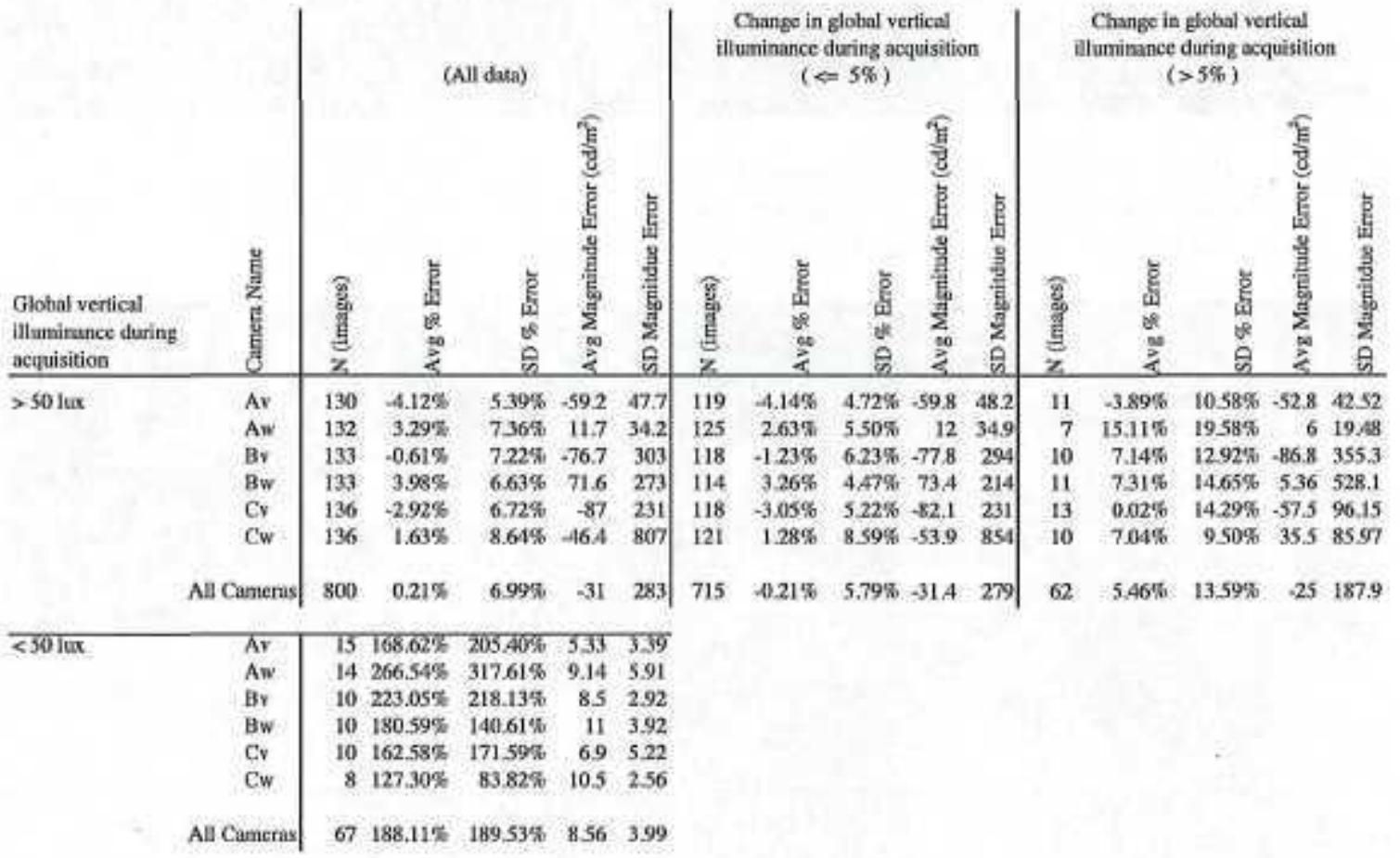




\subsection{Test and Reference Conditions}

Two, six month, solstice-to-solstice phases of field testing were defined. Phase I evaluated interior shading systems (Figure 11) and Phase II evaluated exterior shading systems (Figure 13). For Phase I, the period of measurement was from December 21, 2007 to June 21, 2008. For Phase II, the period of measurement was from June 21,2008 to June 21,2009 . To serve as a simple benchmark to judge test conditions against, two reference conditions were defined: a "manually-adjusted" interior Venetian blind or fabric roller shade. A description the characteristics of each system related to interior daylight distribution is given in Appendix Table 1, and operation and material characteristics are provided in Appendix Tables 2 and 3. A detailed description of hardware and operation is given in [Lee et al. 2009].

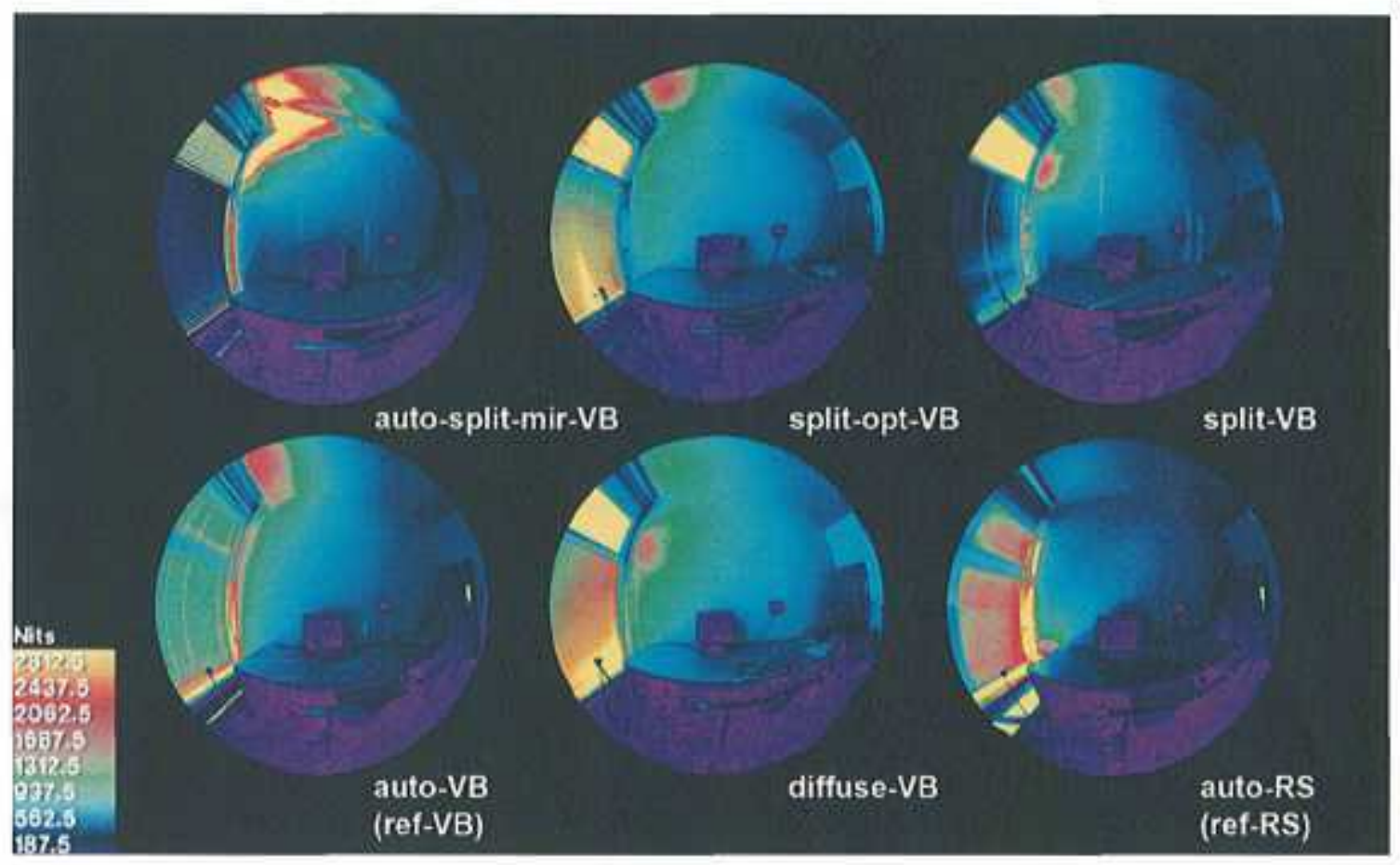

Figure 11. Phase I interior shade test conditions shown with falsecolor tone-mapping (yellow $\geq 3000 \mathrm{~cd} / \mathrm{m}^{2}$ ). The ref-VB was identical to the auto-VB, but seasonally adjusted to block direct sun. The ref-RS was

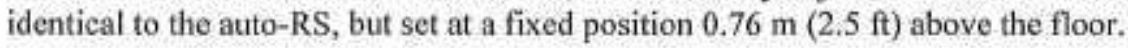

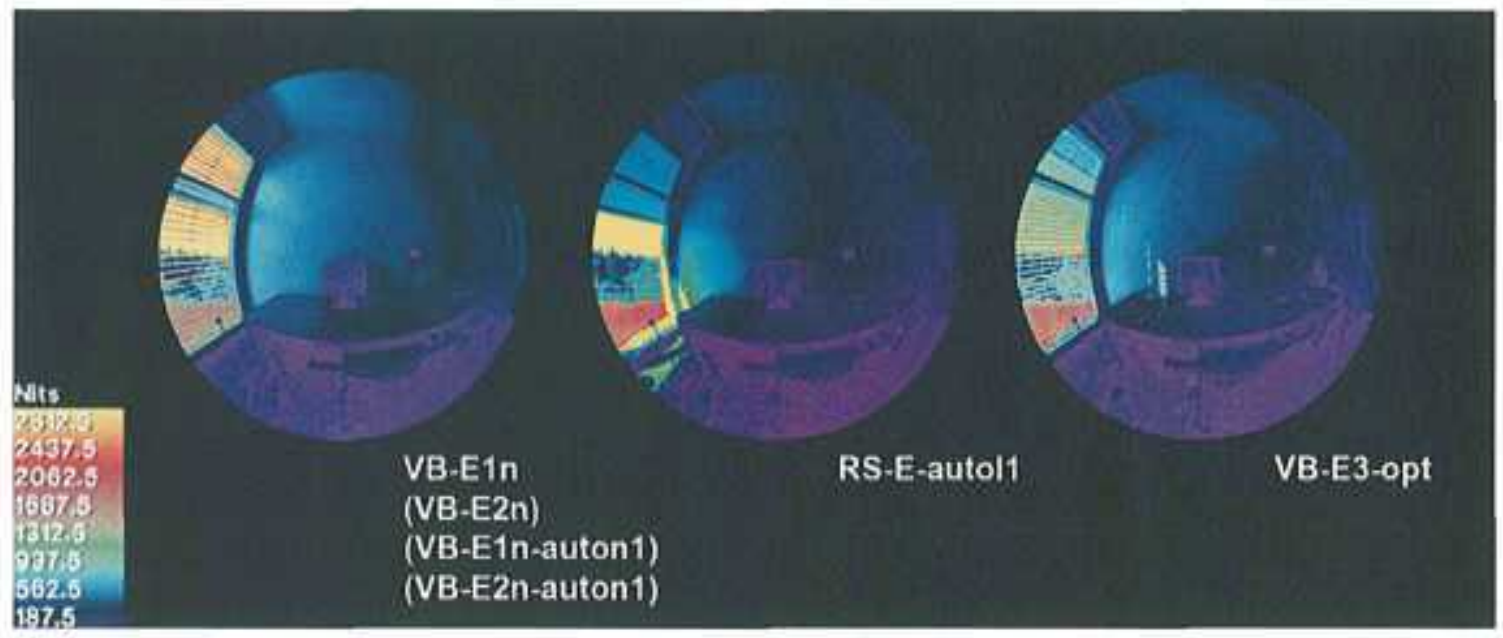


Figure 13. Phase II exterior shade lest conditions shown with falsecolor tone-mapping (yellow $\geq 3000$ $\mathrm{cd}^{\prime} / \mathrm{m}^{2}$ ). The VB-E2n, VB-E $1 n$-auton, and VB-E2n-auton (indicated in palenthesis) are similar in appearance to the VB-E In but involyed eilher a more open upper region (E2), autonation (auton 1), or both.

\subsection{Classification of sky conditions}

Sky conditions were expetted to have a significant influence on visual comfort outcomes Therefore, a sky classification for oach test day was determined using the method developed by [Darula and Kittler, 2004]. The classification is based on two parameters; the fraction of time, $s$, that the direct normal irradiation (measured using a pyroheliometer) exceeds $120 w^{\prime} / \mathrm{m}^{2}$, and $U$, the natural logarithm of the average of the absolute values of the change in global horizontal illuminance (lux) over a one-minute span. If $s$ is less than 0.03 , then conditions are considered to be overcast. If $s$ is greater than or equal to 0.75 , conditions are characterized as clear. For solar fractions between this range, if $U$ is less than $(10-6 s)$, conditions are considered cloudy, otherwise they are considered dynamic. The resulting number of test days and sky conditions are summarized in Table 2.

Table 2 Summary of Ploase I and Phase [l sky conditions

\begin{tabular}{|c|c|c|c|c|c|c|c|c|c|c|}
\hline \multirow{2}{*}{$\begin{array}{l}\text { Phase I } \\
\text { Tesa Condition }\end{array}$} & \multirow[b]{2}{*}{ Orientation } & \multicolumn{5}{|c|}{ Numpter of Days } & \multicolumn{4}{|c|}{ Frection of All Sky Conditions } \\
\hline & & $\mathbf{N}$ & chear & clọudy & dyanimte & overcast & clear & doudy & dynsmic & overcasl \\
\hline \multirow{2}{*}{ anto-split-tntr-VB } & VDI & 42 & 27 & 3 & 7 & 3 & 6.64 & 6.52 & 0.17 & 6.07 \\
\hline & witrdow & 45 & 30 & 5 & 7 & 3 & 0.62 & 0.13 & 0.18 & 0,08 \\
\hline \multirow[t]{2}{*}{ auto-VB } & VDT & 16 & 10 & 1 & 4 & 1 & 0.62 & 0.06 & 0.25 & 0.06 \\
\hline & Window & 15 & 9 & 1 & 4 & 1 & 0.60 & 0.07 & 027 & 0.07 \\
\hline \multirow[t]{2}{*}{ splil-optVB } & VDT & 35 & 21 & 3 & 9 & 2 & 0.60 & 0.09 & 0.26 & 0.06 \\
\hline & window & 35 & 2] & 3 & 9 & 2 & 0.60 & 0.09 & 026 & 0.06 \\
\hline \multirow[t]{2}{*}{ splitil-VB } & VDT & 29 & 22 & 0 & 7 & 0 & 0.76 & 0.00 & 024 & 0.00 \\
\hline & window & 31 & 21 & 0 & 7 & 3 & 0.68 & 0.00 & 0.23 & 0.10 \\
\hline \multirow[t]{2}{*}{ dfffugt-VB } & VIJ'Y & 26 & 19 & 1 & 4 & 2 & 0.73 & 0.04 & 0.15 & Q.08 \\
\hline & window & 26 & 19 & 1 & 4 & 2 & 0.73 & 0,04 & 0.15 & 0.08 \\
\hline \multirow[t]{3}{*}{ aшo-RS } & VDT & 26 & 12 & 3 & 4 & 7 & 0.46 & 0.12 & 0.15 & 0.27 \\
\hline & Windkw & 26 & 13 & 3 & 4 & 6 & 0.50 & 0.12 & 0.15 & 0.23 \\
\hline & & & & & & average & 0.63 & 0.07 & 0.21 & 0.10 \\
\hline
\end{tabular}

Phase II

\begin{tabular}{|c|c|c|c|c|c|c|c|c|c|c|}
\hline Tesl Condition & Orlentolion & $\mathbf{N}$ & slear & cloudy & dynamic & opereast & clear & clonudy & dynanic & overcast \\
\hline \multirow{2}{*}{ VE-EIn } & VIDT & 45 & $30^{\cdots+m}$ & 2 & 7 & 6 & 0.67 & 0.04 & 0.16 & 0.13 \\
\hline & Hindow & 44 & 29 & 2 & 7 & 6 & 0.66 & 0.05 & 0.16 & 0.14 \\
\hline \multirow{2}{*}{ VB-Eln-aulonl } & VDT & 76 & 3J & 9 & 22 & 14 & 0.41 & 0.12 & 0.29 & 0.18 \\
\hline & Window & 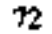 & 30 & $g$ & 20 & 13 & 0.42 & 0.12 & 028 & 0.18 \\
\hline \multirow[t]{2}{*}{ VH-E2 2$]$} & VDT & 33 & 22 & 2 & 8 & 1 & 0.67 & 0.16 & 024 & 0,03 \\
\hline & window & 32 & 21 & 2 & 8 & 1 & 0.645 & 0.156 & 025 & 0.03 \\
\hline \multirow[t]{2}{*}{ 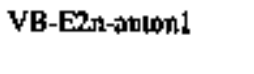 } & VDT & 24 & 14 & 3 & 4 & 3 & 0.58 & 0.12 & 0.17 & 0.12 \\
\hline & wirtdow & 24 & 14 & 3 & 4 & 3 & 058 & 0.12 & 0.17 & 0.12 \\
\hline \multirow{2}{*}{ RS-Esuronl (vs. ref- } & VDT & 49 & 28 & 5 & 13 & 3 & 0.57 & 0.1 & 0.27 & 0.06 \\
\hline & window & 47 & 26 & 5 & 13 & 3 & 055 & 0.11 & 0.28 & 0.06 \\
\hline \multirow[t]{2}{*}{ VB-E3opt } & VDT & 45 & 25 & 6 & 10 & 4 & 0.56 & 0.13 & 0.22 & 0.09 \\
\hline & mindow & 45 & 25 & 6 & 10 & 4 & 0.56 & 0.13 & 0.22 & 0.09 \\
\hline \multirow[t]{3}{*}{ RS-[-auldoll } & VDT & 56 & 32 & 5 & 14 & 5 & 0.57 & 0.09 & 0.25 & 0.09 \\
\hline & window & 47 & 29 & 3 & 13 & 2 & 0.62 & 0.06 & 0.28 & 0.04 \\
\hline & & & & & & average & 0.58 & 0.09 & 0.23 & 0.10 \\
\hline
\end{tabular}




\section{IESNA region-brased contrast ratio limits}

The IESNA has developed guidelines for acceptable levels of non-uniformity expressed in terms of luminance ratjos between surfaces in the field of yiew. The basis for the guideline is the physiological phenomenon called transient adaptation, a phenomenon associated with reduced visibility after viewing a higher or lower luminance than that of the task [IESNA 2005]. To avoid visual performance decrements, a maximum allowable contrast of $[1: 3: 10]$ is permitted between the task, surroundings, and background.

Luminance maps are particulatly well suited to the analysis of luminanee ratios, as any number of arbitrarily shaped regions can be detined during analysis. In this study, regions were defined by creating a unique bitmap mask (Figure 15) and a process was implemenled using Radiance to compute the average luminance for each of the masked regions. The visual task was defined as a visual display terminal (VDT) with a constant luminance of $200 \mathrm{~cd} / \mathrm{m}^{2}$, leading to discomfort thresholds of $600 \mathrm{~cd} / \mathrm{m}^{2}$ for "surrounding" regions (i.e., $1: 3$ ), and $2000 \mathrm{~cd}^{\prime} \mathrm{m}^{2}$ for "background" regions (i.e., $1: 10$ ).

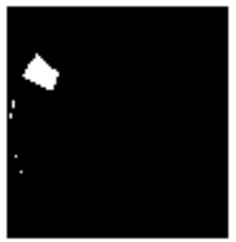

Itwerthinkm

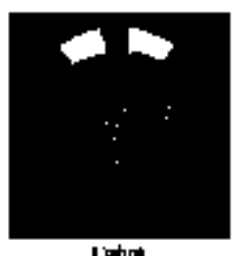

I thin

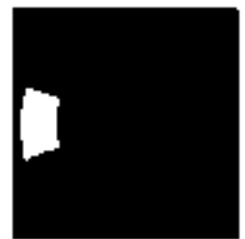

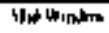

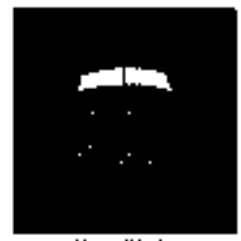

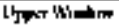

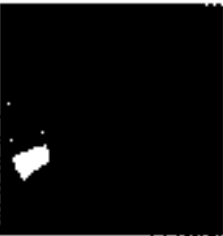

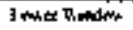

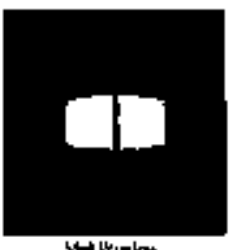

int itingon

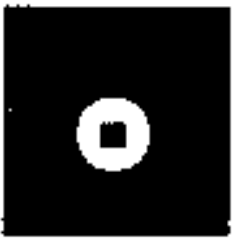

VIII Gement

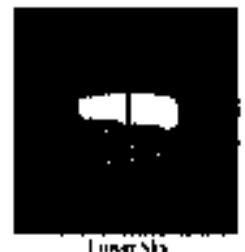

| 1 आता

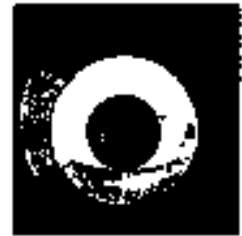

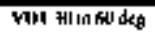

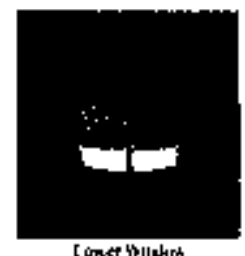

[onke thildirh

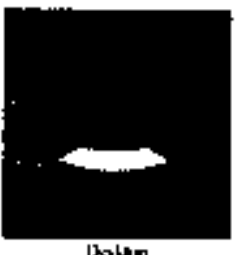

|kalap

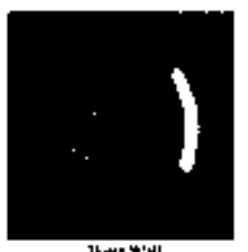

Figure 15. Itlustration of the bitmap masks used to define regions in images acquired from the VDT-facing view point (upper row) and window-facing view point (lower row). For illustrative purposes, the bilmap mask (indicated in white) is superimposed on a generic image from each respective view orientation.

\section{1. Anatygis of region-luminance dato}

The analysis of region luminance data focused on differentiating between shading systems based on the frequency and degree of threshold exceedance produced by each pre-defined region. This method was used to evaluate 12 regions for each of 14 test conditions under four different sky conditions to quickly identify the regions and sky conditions that produced the greatest discomfort conditions.

As an example of this method (using Phase I data for the Window-facing orientation), Figure 17 illustrates the frequency and degree of threshold exceedance resulting from exceeding the IESNA recommended contrast ratio limits for the window regions under cleat sky conditions. For each window region in Figure $17_{\text {, }}$ there are two accompanying figures immediately below. The bottom figure indicates the percent of time ( 6 AM to 6 PM Standard Time) that the luminance threshold ( $\left.2000 \mathrm{~cd} / \mathrm{m}^{2}\right)$ was exceeded under all clear sky conditions. Data for all Phase I shading systems, including the reference condilions (indicated in brackets), are shown on the same plot (identified by a letter code).

As an indicator of the magnitude of threshold exceedance, the middle figure summarizes the distribution of values observed above the luminance threshold. The data are ordered and the first (Q1), second (Median) and llikd (Q3) quartiles are identified by horizontal lines. The median is indicated by a bold line within the box that is drawn around the inner quartile range (IQR). The whiskers extend to the smallest observation (i.e., $2001 \mathrm{~cd} / \mathrm{m}^{3}$ ) and latgest observation (i.c., tho maximum luminance recorded for that region). 
This method enabled the identification of general trends in relative perlomance between systems, for example, the automated Venetian biind systems $(A, B)$ controlled window luminance to within desired limits better than the static (i.e., seasonally adjusted) blind systems for all four regions (Figure 17 ). In addition, the method enabled the differentiation between systems based on the magnitude of "lailute" conditions. As an example, the upper window region of the split-opt-VB, split-VB, and diffuse-VB test conditions resulted in significantly greater luminance levels when the luminance threshold was exceeded compated with other systems.

Finally, this method enabled the performance of individual systems to be assessed in greater detail spalially. For example, the performance of the split-opt-VB was better than the split-VB for the tupper and lower window regions, but significantly worse for the mid and lower shy regions. The substantial variation in performance between regions (both within and across systems) illustrates the need for detailed analysis of innovative factade systems when the system is divided into different functional roles.

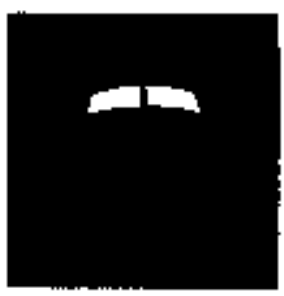

Upper whinow

Disinbulion of yoluts moove
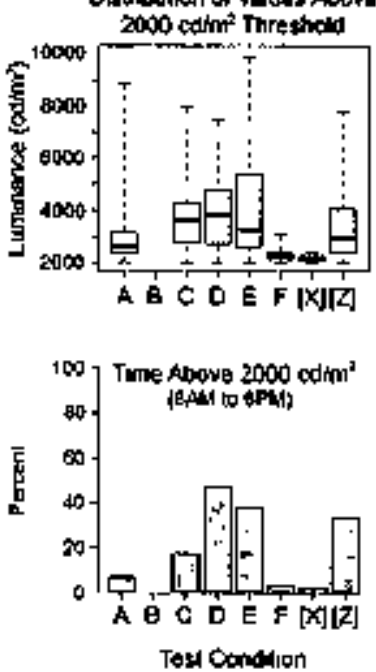

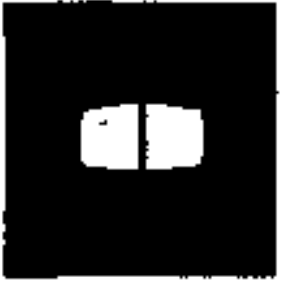

Mid undow
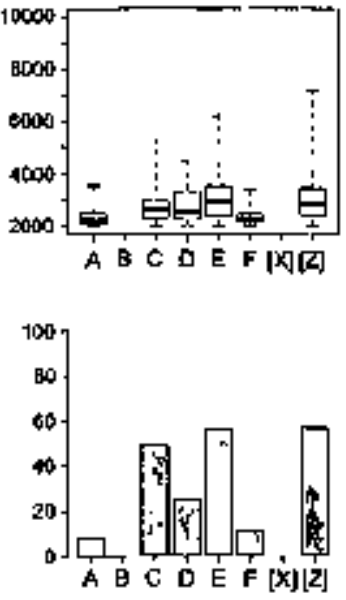

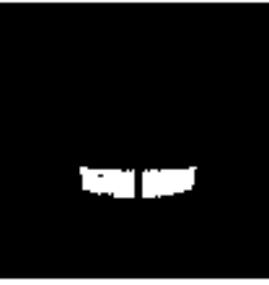

Lowter motodolf
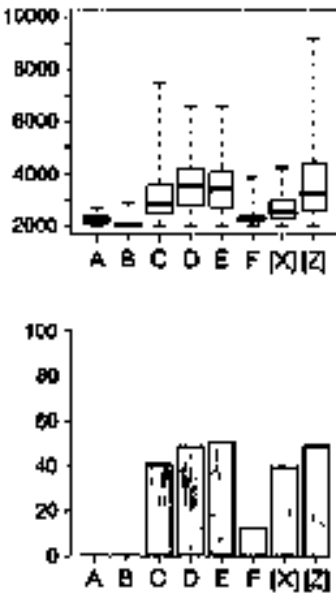

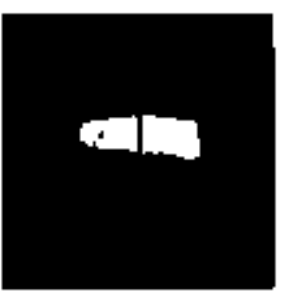

Lower By
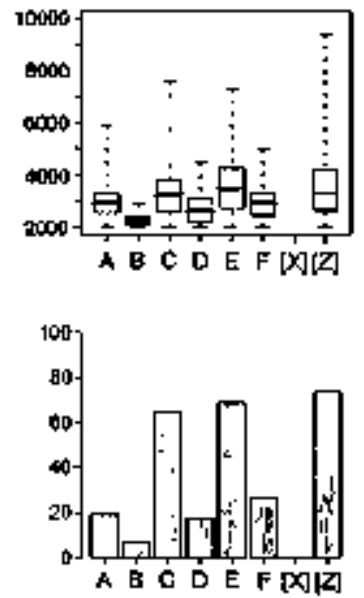

Figure 17. Summaty of luminance values during clear sky conditions for Phase I test condilions (Windowfacing orientation). $A=$ auto-split-mir-VB ( $N=27$ days), B = auto-VB $(N=9), C=$ split-opt- $V B(N=19), D$ $=$ split-VB $(\mathrm{N}=20), \mathrm{E}=$ diffuse-VB $(\mathrm{N}=18), \mathrm{F}=$ auto-RS $(\mathrm{N}=12),[\mathrm{X}]=$ ref-RS $(\mathrm{N}=19),[\mathrm{Z}]=$ ref-VB $(\mathrm{N}$ $=48$ ).

\section{The Daylight Glare Index}

\section{I. Discomfori Glare}

The Ilopkinson-Comell large-source glare index (daylight glate index or DGl) is a metric tonmonly used to evaluatc disennfort glare for large-area souress of glaro such as windows [Hopkinson and Bradley, 1960; IES 1962]. DGL is computed from a formula that was developed to account for the effects of source brightsess, size, location relative to line of sight, and adaptation luminance. Table 3 lists the mean subjective response to values from the DGl formula as measured in envitoninents with windows. 


$$
D G l=10 \log 0.478 \sum_{i=1}^{H} \frac{L_{t}^{1.6} \cdot \Omega^{0.3}}{L_{t}+0.07 \cdot 0^{0.5} \cdot L_{y}}
$$

where,

$L_{x} \quad$ Source luminance $\left(\mathrm{cd} / \mathrm{m}^{2}\right)$

$L_{\phi} \quad$ Background luminance $\left(\mathrm{cd} / \mathrm{m}^{2}\right)$

$\Omega \quad$ Solid angular subtense of source modified for the effect of the observer in relation to the source (sr)

1) Solid angulat subtense of source at the eye of the observer (sr)

Table 4. Subjective correlation to DGJ

\begin{tabular}{ll} 
Glare Criterion & DGI \\
\hline Just perceptibie & 16 \\
Just acceptable & 20 \\
Just uncomfortable & 24 \\
Just inolerable & 28
\end{tabular}

\subsection{Detection of arbirrarify tocated glare sounces}

Although a luminance map provides a highly detailed representation of the visual environment, there remains the challenge of determining what regions in the image constitute a glare source in order to compute glare discomfort metrics such as the DOJ. Addressing this issue is presently dealt with by specifying a threshold value for glare: either an absolute value $\left(e_{,} g\right.$., all sources above $\left.1000 \mathrm{~cd}^{\prime} / \mathrm{m}^{2}\right)$ or a ratio beiween a given pixel and the average luminance of the task or entire scene (e.g., 4:1). There is currenlly limited guidance for what this threshold yalue should be, or what method to use in order to represent the giare sensitivity of a human obscrver. In the development of evalglare, a lool to predict the probability of discomfort glarc (DGP) from hemispherical luminance maps, Wienold and Christoftersen [2006] defined gilare as any pixel four times greater in luminance than the average luminance of a circular visual task zone with an angle of $\sim 0.53 \mathrm{sr}$. However, Wienold and Christoffersen did not indicate how the ratio of 4:I was amived at in favor of other possible ratios. Evalgjare allows the user to select from multiple methods of glare detection (e.g., scenebased, task-based, and absolute) as well as specify the threshold. If the task-based method is chosen, the too] enables the user to define a circular task zone by specifying the centroid and solid angle.

In this study. glare sources were detected using the Radiance program, findglare [Ward 1992]. The approach used by findgiare to identify glare sources is called "thresho|ding," where the image is divided orthogonally into equal samples and if a particular sample is above a designated threshold value, then findglare assumes it must be part of a glare source. In this study a threshold value of $1000 \mathrm{~cd} / \mathrm{m}^{2}$ was used to deleet glare sources. This value corresponds to a ratio of 5:1 relative to the task defined in this study (a VDT of average luminance $=200 \mathrm{~cd} / \mathrm{m}^{2}$ ). When a sample above the threshold value is found, it is merged with neighboring contiguous glare samples. Two glare samples are considered contiguous if they are separated by at most one non-glare sample. This allowed separalion is to avoid the breakup of something like a window with Venetian blinds into an unreasonable number of sources. A glare source may have any number of holes in it and still be considered contiguous. The sample parameter was specified to generate a sample size of 2 pixels by 2 pixels, enabling the differentiation of glare sources located relatively close together, The output of findglare is the centroid, solid angle, and average luminance of each glare source itentified. In this study, these values were then processed by another Radiance progtam glarendx to compute the DGI.

\subsection{Weighting of Time-Series DGI Data}

Because the DGI in a highly daylit space can cover a wide range of subjective values over the course of n day (from imperceptible up to uneomfortable or cven intolerable glate), simple averaging of all observed values 
can easily result in a summary value of "imperceptible" glare and therefore lead to misleading conclusions. There is no agreed upon procedure for handling this type of problem.

To address this problem, a weighted daylight glare index (DGI $)$ sensitive to infrequent periods of perceptible-to-uncomfortable glare was implemented [Carmody 2004]. The weighting formula is relatively sensitive to extreme values of discomfort glare yet capable of discriminating between cases with single large excursions and cases with multiple but just slightly smaller excursions from the base value. The returned $\mathrm{DGI}_{\mathrm{w}}$ value gives an average that is sensitive to excursions from a base value if they occur at a frequency of 1 percent or more and has a scale that is the same as that defined for an individual DGI value (e.g., $20=$ "just noticeable", 22 ="just uncomfortable" etc.). We therefore constrained the minimum and maximum values of DGI and calculated a $\mathrm{DGI}_{w}$ from the constrained values for each day using the equation below. An example of the weighting method applied to 144 observations of the DGI is shown in Figure 19.

If DGI $<6$, then set DGI to 6 , or if DGI > 32, then set DGI to 32 ,

else, $\mathrm{DGI}_{\mathrm{w}}=4 * \log _{10}\left[\right.$ mean(10 $\left(0^{(\mathrm{OG} / 4)}\right]$

where, DGl $=$ Measured 5-min DGI data over the 12-h period from 6 AM to $6 \mathrm{PM}$.

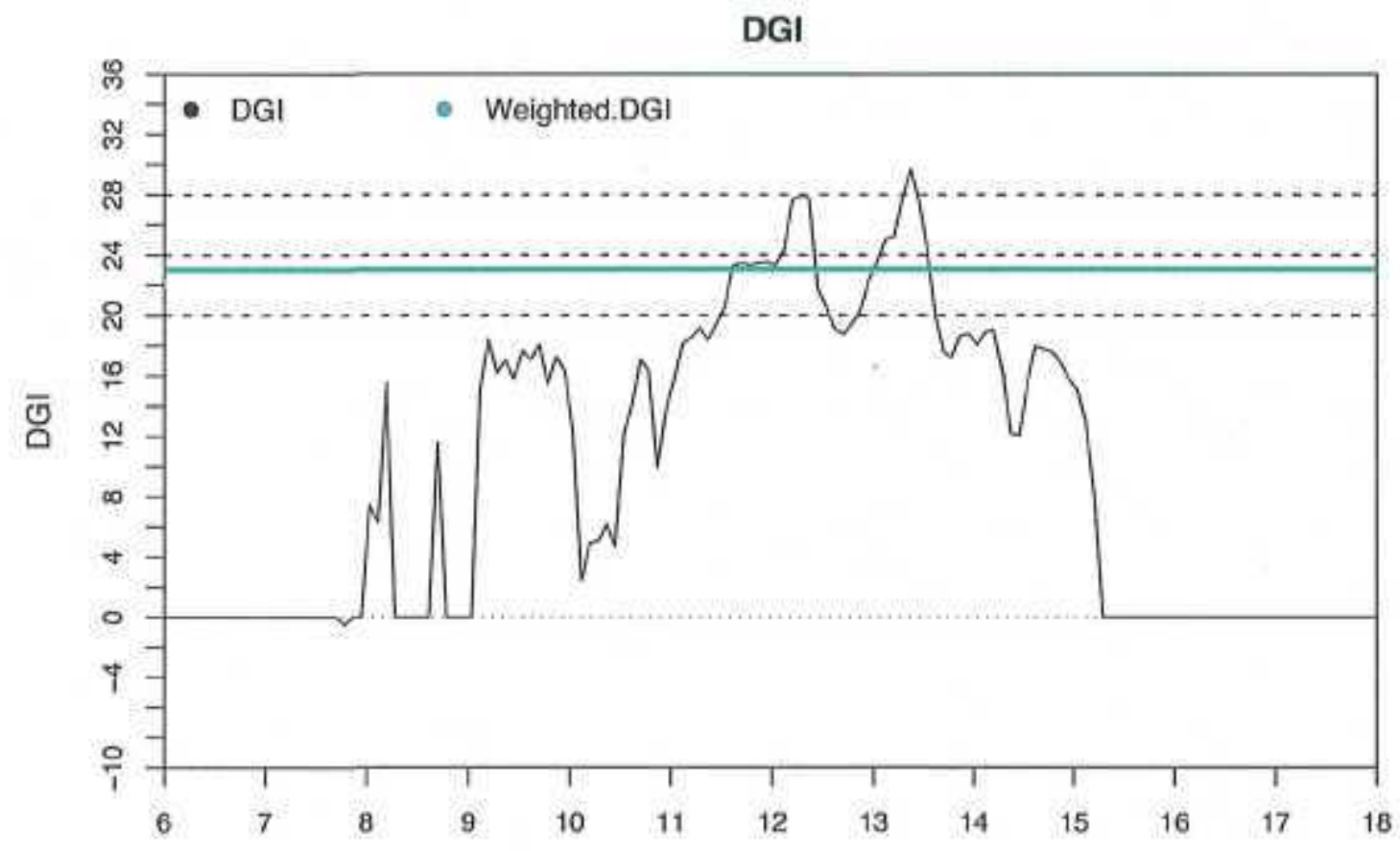

Hour on 20081031

Figure 19. Illustration of the dynamic variation of DGI data over one 12 -h day and the corresponding DGI $_{w}$ value (solid cyan line). The dotted horizontal lines correspond to the following semantic glare discomfort thresholds: 20 = "Just acceptable," 24 = "Just uncomfortable," 28 = "Just intolerable." 


\subsection{Analysis of DGI Dato}

The DGI, analysis focused on two goals 1) differentiating system petformance across seasonal variation in sun and sky conditions and 2) providing an "overall" summary of visual comfort performance for the solstice10-solslice interval. Afthough the $\mathrm{DGI}_{\mathrm{w}^{\prime}}$ analysis indicated discomfort conditions under non-clear sky conditions, the unequal number of sky conditions recorded for etch system combined with the uneven distribution of non-clear conditions throughout the test intervals resulted in the analysis focusing on clear sky data.

Using the auto-split-mir-VB as an example, Figure 21 illustrates both the taily and seasonal varialbility of time-series DGl data that was recorded for clear sky conditions during Phase I testing. For each day (indicated on the $x$-axis in MMDD format) the 5-minute time-series DGI data is plotted on the $y$-axis and color-coded by magnitude of discomfort (c.B., yeliow corresponds to "just uneomfortable"). The green lines indicate the times when seasonal slat adjustnents were magde to the ref-VB. This graphic technigue enables one to visualize the lime and magnitude of visual discomfort for each test condition and provided feedback to ingprove the operation of dynamic systems by indicating specific times for more detailed diagnostics. 


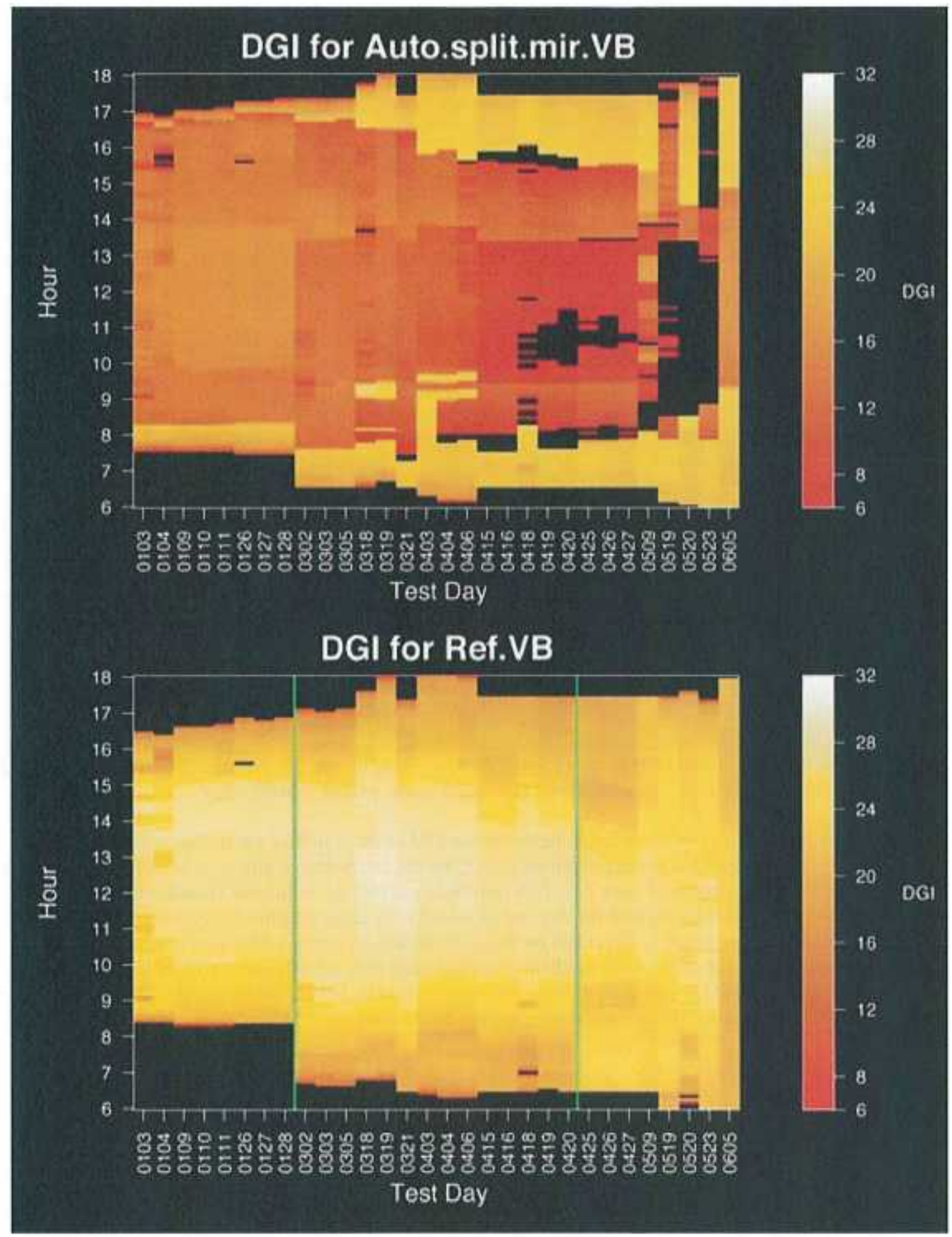

Figure 21. Side-by-side comparison of the auto-split-mir-VB versus the ref-VB under simultaneous exterior solar conditions. Issues related to image acquisition resulted in missing data on some days in the early morning ( $6 \mathrm{AM}$ to $6: 30 \mathrm{AM}$ ) and evening (5:30 PM to $6 \mathrm{PM})$ Standard Time. The vertical green lines indicate the times when seasonal slat adjustments were made to the ref-VB. 


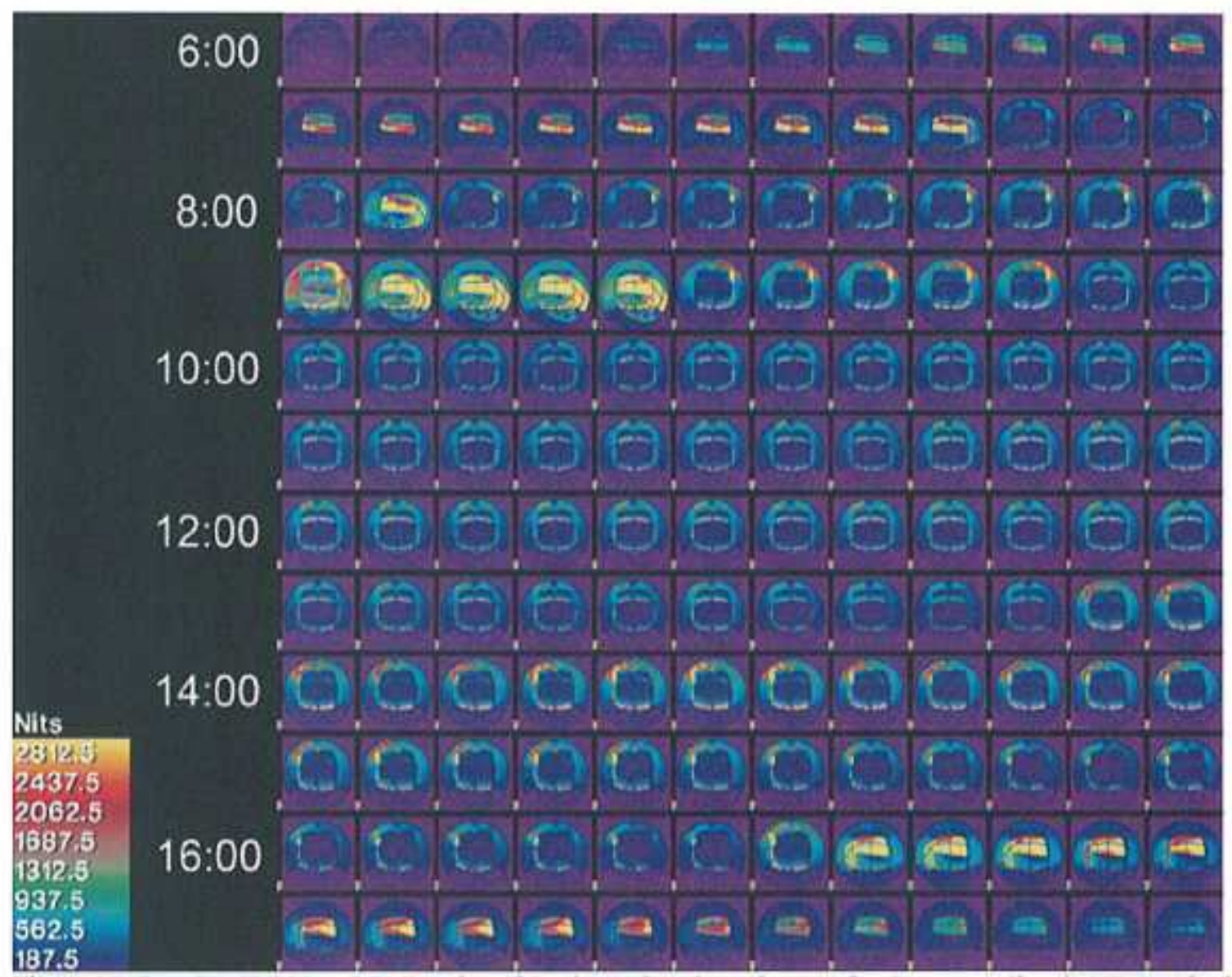

Figure 23. One day ( 6 AM to $6 \mathrm{PM}$ ) series of 5-minute time-lapse images for the auto-split-mir-VB acquired on March 18, 2010 during clear sky conditions. Falsecolor scale: yellow $\geq 3000 \mathrm{~cd} / \mathrm{m}^{2}$.

As an example, the periods of discomfort indicated around 9AM on March 18 for the auto-split-mir-VB (Figure 21) were investigated in greater detail by compiling the entire day of images into a time-lapse movie using a falsecolor tone-mapping (Figure 23). This technique enabled us to directly visualize the scenes that resulted in glare discomfort throughout the day and to identify the causes. In the above example (Figure 23), the glare discomfort was a result of direct sun on the sidewall and an unshaded view of bright sky. These conditions existed while the direct solar irradiance on the facade was insufficient to trigger the deployment of the blind due to position of the sun at an oblique angle to the facade, but sufficient to cause discomfort for an unacceptable period of time. This information was later used to improve the control algorithm used to control this system. 


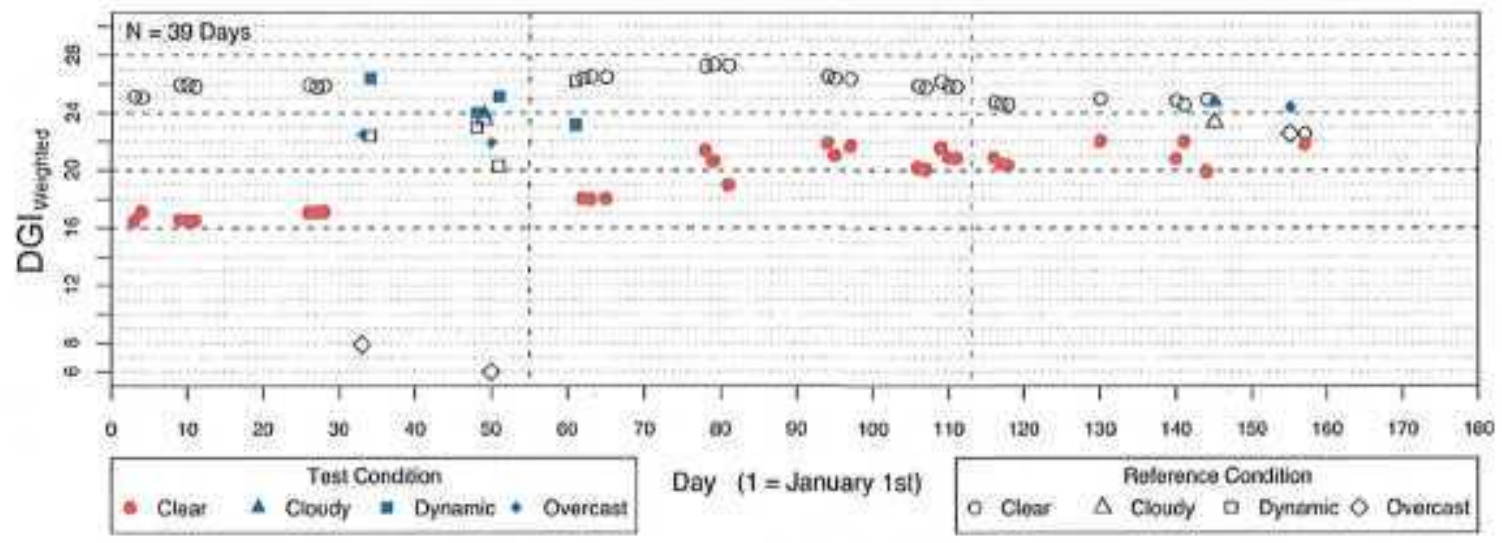

Figure 24. Plot of $\mathrm{DGI}_{w}$ values for Phase I testing of the auto-split-mir-VB paired against the ref-VB (window-facing orientation). Values are coded by Darula sky classification. Only clear days (red dots) were used in the summary analysis. The vertical lines indicate the times when seasonal slat adjustments were made to the ref-VB.

Figure 24 illustrates the seasonal distribution of $\mathrm{DGI}_{\mathrm{w}}$ values for the auto-split-mir-VB and ref-VB pairing. In this figure, $\mathrm{DGI}_{\mathrm{w}}$ values for non-clear sky conditions are included for illustrative purposes. The increasing trend in $\mathrm{DGI}_{w}$ values from winter to summer reflects the increasing periods of visual discomfort in the morning and evening (indicated in yellow in Figure 9) that occurred as the system remained retracted until the exterior vertical illuminance threshold was exceeded and the blind deployed.

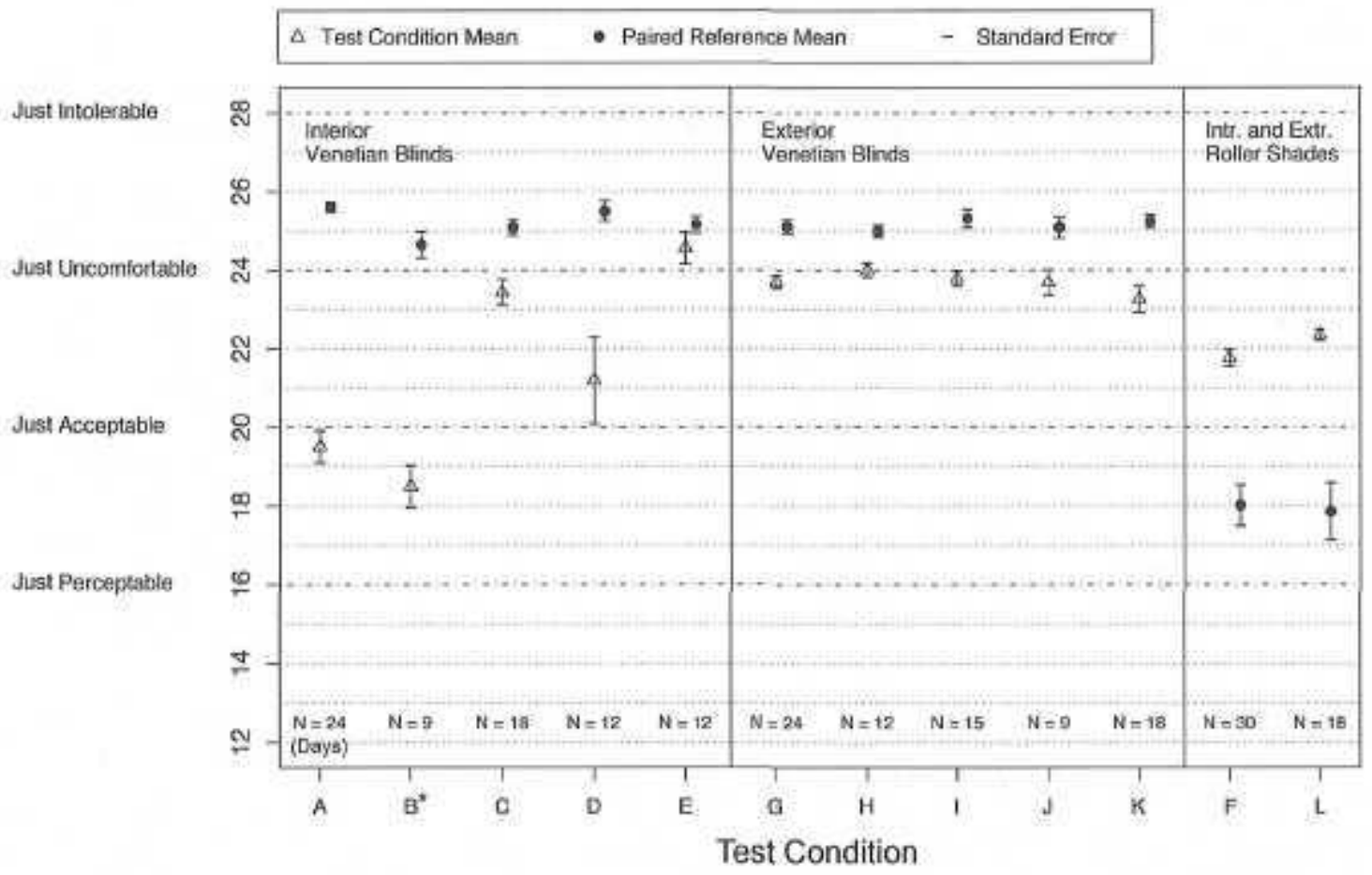

Figure 25. Plot of the mean and standard error of $\mathrm{DGI}_{\mathrm{w}}$ values for each interior and exterior test condition (xaxis) compared against its reference condition ( $\mathrm{y}$-axis) for the window-facing orientation during clear sky conditions.

Figure 25 summarizes the $\mathrm{DGI}_{\mathrm{w}}$ values for Phase I and II shading systems for the window-facing orientation under clear sky conditions. The summary was created by taking the average of the $\mathrm{DGI}_{\mathrm{w}}$ values over the 
șolstice-to-solstice interval for each test condition, using an equal nurnber of test days from each interval of seasonal slat-angle adjustment (e.g., "winter, "equnnox," "summer") to not blas the Iesults toward a system that performed better or worse during one particular time of year. The standard error is provided as an: indicator of the variability in the observed $\mathrm{DGG}{ }_{\mathrm{p}}$, values. Data for this figure and letter-code for each system are given in Table 5. All results include equal groups of test days from each third of the solstice-to-solstice test interval except for test condition " $B$ " (auto-VB), which due to operational issues, resulled in 2 test days in the first thitd, no days in the middle, and 7 days in the final third. Because glare conditions were generally more severe at lower sun angles, it is expected that an equal sampling or test days would result in a greater summary $\mathrm{DGl} \mathrm{l}_{\mathrm{r}}$ score for this test condition.

Table S Summary of $\mathrm{DGl}_{\mathrm{w}}$ data

\begin{tabular}{|c|c|c|c|c|c|c|}
\hline \multirow[b]{2}{*}{ Tex Condruon } & \multirow[b]{2}{*}{ Codk } & \multicolumn{3}{|c|}{ |Whdow-Faring Cantern } & \multirow[b]{2}{*}{ Mean icf } & \multirow[b]{2}{*}{ SE ref } \\
\hline & & $\mathbf{N}$ & Mean texh & SE ksl & & \\
\hline aLAo splu mer-YE & A & 24 & -195 & 031 & 256 & 012 \\
\hline molve VB & B & 9 & 185 & 053 & 246 & 034 \\
\hline spht-opt-vB & c & 18 & 234 & 032 & 251 & 020 \\
\hline spltt-vB & D & 12 & $2 J 2$ & 1 II & 255 & 026 \\
\hline dilfuse VB & E & 12 & 246 & 040 & 252 & 021 \\
\hline VE-Eln & G & $2 \pi$ & 237 & 078 & 251 & 017 \\
\hline YB-EIta-taukoul & H & 12 & 240 & 0 19 & 250 & 015 \\
\hline VB E2n & I & 15 & 238 & 020 & 253 & 023 \\
\hline VB-E2-2n-4uton] & J & g & 237 & 032 & 251 & 026 \\
\hline VB.ESopt & $\mathrm{x}$ & 18 & 232 & 033 & 252 & 017 \\
\hline RS.I\&Atato] & $\mathbf{F}$ & 30 & 218 & 022 & TBO & 052 \\
\hline RS-E-pationI & L & 18 & 223 & $0 / 4$ & 139 & 073 \\
\hline
\end{tabular}

\begin{tabular}{|c|c|c|c|c|}
\hline \multicolumn{5}{|c|}{ VTT.Facing Camera } \\
\hline $\mathbf{N}$ & Mean te日l & SE $\cos x$ & Mean res & SE ref \\
\hline $2 T$ & 119 & 027 & 135 & 036 \\
\hline 10 & 32 & 019 & 123 & 050 \\
\hline 18 & 122 & 032 & 132 & 040 \\
\hline 12 & 103 & 052 & 135 & 057 \\
\hline 12 & 138 & 042 & 132 & 047 \\
\hline $2 T$ & 1199 & 627 & 133 & 036 \\
\hline 12 & 116 & 027 & 134 & 029 \\
\hline 18 & 128 & D 315. & 136 & 040 \\
\hline 9 & 126 & 074 & 138 & 065 \\
\hline IB & 123 & 037 & 115 & 0.31 \\
\hline 33 & 132 & 027 & 102 & 045 \\
\hline 18 & 137 & (6) 89 & 100 & 062 \\
\hline
\end{tabular}

\section{Discussion}

This paper tllustrales two methods to achieve summary indicators of visual comfort based on performance over solstice-to-solstice condutions using existing metrics. The analysis focused on addressing two quesrions.

1) Do exstsng metrics and summary indices computed from iumunce maps enable differeatrotson benveen systems"

Both methods enabled general Irends in performance between groups of shading systems to be identified and these trends were generally consistent between the two metlods. For example, of all Venetian blind systems tested, the interior automated shading systcms (auto-sp lit-mir-VB, auto-VB) resulted in the lowest summary DGI scores (Figure 25) and the least luminance threshold excedance for the window regions (Figure 17) In addution, both methods indicaled that the ref-VB performed the worst of all syslems tested, with the highest DGI ${ }_{n}$ score (Figure 25) and in general the greatest periods of exceedance for most pre-defined regions (Figure 17). However, the methods were not consistent in assessing the performance of the static interior subdivided systems (split-opt-VB, split-VB), where the split-VB resulted in a lower summary DGI w score than the split-opt-VB, yet exceeded the luminance threshold for a greater period of lime for the upper and lower window regions.

\section{2) What value can tme-lapse smaging add over more conventronat methods of vistat comfort assessment?}

Two benefits were found in this study. The first benefit, demonsirated in Secton 3, is the ability to subdivide regions of the image into an arbitrary number of zones of any arbitrery shape. This capabılity enabled us to differentiale performance betwecen systems with greater spatial detail. For example, the performance of the split-opt-VB was better than the split-VB for the upper and lower window regions, but significantly worse for the med and lower shy regions (figure 17). The substantial variation in performance between regions (both within and across systems) illustrates the need for detailed analysis of innovative facade systems when the system is divided into different functional roles. 
The second and perhaps more significant benefit is that an HDR image can be used to directly visualize the magnitude and distribution of light throughout the day. Used primarily as a diagnostic technique in this study, daily sets of HDR images compiled into time-lapse movies enabled the performance of dynamic shading and light redirecting systems to be evaluated and improved by visually identifying the conditions that caused discomfort (Figure 23).

\section{Conclasions}

Six-nonth, solstice-to-solstice experimental tests were conducted of torth conventional and innovative interior and exterior shading systems on south-facing, large-area windows at a full-scale daylight test facility, localcd in a predorminantly sunny climate in Berkelcy, California. Thess systems used a variety of strategies, including optics, subdivision of the window wall into a lower view and upper daylighting zone, and automated controls, with the goal of achieving a more balanced and comfortable luminous environment.

l'he objective of this study was to explore how calibrated high dynamic range (HDR) images (luminance maps) acquired in real world daylit environments can be used to characterize, evaluate, and compare visual comfort conditions of innovative facade shading and light-redirecting systems. Detailed ( 1536 x 1536 pixel) luminance maps were time-lapse acquired at 5 -min intervals over a 12 -h period from two view positions in an anoccupied full scale testbed facility. These laminance maps were analyzed using a weighted Hopkinson Cornel! Daylight Glare Index (D-G) and the IESNA recommended contrast ratio liınits lo quantify how innovalive interior and exterior shading systems compared to conventional systems under real sun and sky conditions over a solstice-to-solstice test interval. Glare sources for the DGl calculation wcre dctected using the Radiance findgiare tool assuming a threshold value of $1000 \mathrm{~cd} / \mathrm{mr}^{2}$. Contrast ratios were based on the luminane of uset-defined masked regions of the luminance map, assuming a compuler-based task with a visual display terminal (VDT) average luminance of $200 \mathrm{~cd} / \mathrm{m}^{2}$.

Based on the results of this study, the following conclusions were made:

1. Both the weighted DGl and the IESNA recommended contrast ratio limits enabled general trends in performance between groups of shading systems to be identified and these trends were generally consistent between the two indicutors.

2. Compared to existing methods of analysis thal define the entire window as a single glare source, Iuminance maps indicate thiat the magnitude and duration of visual disconfort varied significantly for many systems across the "masked" regions defined for the window and illustrate the need for more detailed spatial analysis when assessing the visual comfort performance of innovative facade systems.

3. Daily sets of luminance maps compiled into movies with a false-color tone-mapping can provide a significant advantage over conventional visual discomfort indicators when used as a diagnostic technique to visualize, assess, and improve the performance of contol algorithms for automated shading and light redirecting systems.

Luminance maps, corrected for lens light fall off (vignetting) and calibrated against an adjacent íluminance sensor, are reasonably accurate on average under dynamic sky conditions when the change in global vertical illuminance during acquisition is below $5 \%$ avg. \% error of the six cameras $=-0.21 \%$, standard deviation w $5.79 \%, \mathrm{~N}=715$ inages). However, luminance data becomes significantly less accurate when the change in global vertical illuminance at the lens during acquisition exceeds $5 \%$ (avg. \% error of the six cameras $5.46 \%$, standard deviation $=13.59 \%, \mathrm{~N}=62$ images $)$.

\section{Acknowledgments}

We would like to thank our L.BNI, colleagues, Daniel Fuller, Dennis DiBartolomed, and Chad Howdey Goudey for their assistance on this project. This work was supported by the Assistant Secretary for Energy 
Efficiency and Renewable Energy, Building Technologies Program, of the U.S. Department of Energy under Contract No. DE-ACO2-05CHI 231 and the California Energy Commission through its Public lnterest Energy Research (PIER) Program on behalf of the citizens of California.

\section{References}

Carmody J, Selkowitz SE, I.ee ES, Arasteh D, Willmert T. 2004. Window systems for high-performance buildings. W.W. Norton \& Co. New York, London, 362-363.

Clear RD, Inkarojirit V, Lee ES. 2006. Subject responses to electrochtomic windows. Energy and Buildings. 38(7): 758-779.

Darula S, Kittler R. 2004. Sunshine duration and daily courses of illuminance in Bratislava. Intemational Journal of Climatology $24: 1777-1783$.

Debevec PE, Malik I. I997. Recovering high dynamic range radiance maps from photographs. SIGGRAPH, 369-378.

Fan D, Mardaljevic J. 2009. HDReapOSX. How to automate capture using a Mac Mini less k/b and screen.

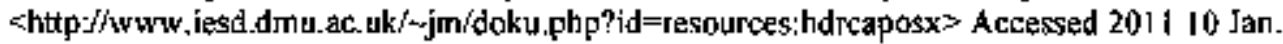

Hopkjnson RG, Bradley RC. 1960. "Glare from very large sources", Illuminating Engineering, 55, 288-297.

Hopkinson RG. 1972. "Glere from daylighting in buildings", Applied Ergonomics, 3, 206-215.

Aschehoug O, Christoffersen J, Jakobiak R, Johnsen K, Lee ES. Ruck N, Selkowitz SE, editors. 2000.

Daylight In Buildings: $A$ source book on daylighting systems and components. A Report of IEA SHC Task 21/ ECBCS Annex 29.

Rea $M_{+}$editor. 2000. The IESNA Lighting Handbook. 9th ed. New York: The Illuminating Engineering Sociery of North America. Luminance ratio limits; ch. 11, pp. 16-18.

Inagnici M, Galvin I. 2004. Evaluation of high dynantic range photography as a luminance thapping Teclinique. Lowrence Berkeley National Laboratory.

shlip//escholarship.org/tc/item/9h6If5118* Accessed 2011 lo Jan.

Lee ES., Selkowitz SE, DiBartolomeo DL, Klenns Jll, Clear RD, Konis K, Hitchcock R, Yazdanian M, Mitchell R, Konstantoglou M. 2009. High performance birilding facade solutions.

California Energy Commission, PIER. Publication number CEC-500-06-041.

Mitsunaga T. Nayar SK. 1999. JEEE Conference on computer visiọn and pattern recognition (CVPR), Vol.I, 374-380.

Nabil A, Mardaljevic f. 2006. Useful daylight illuminances: A replacement for daylight factors. Energy and Buildings. 38(7): 905-913.

Sutter Y, Dumortier D, Fontoynont M. 2006. Tlue Use of shading systems in VDU task offices: A pilot study. Energy and Buildings 38(7): 780-789.

Tuaycharoen N, Tregenza PR. 2007. View and discomfort glare from windows. Lighting Research and Technology. 39(2): 185-200. 
U.S. Green Building Council. 2009. LEED 2009 tor new construction and majot renovations rating system. Version 3.

Ward G. 1991. Real Pixels. Graphics Gems II, edited by James Arvo, Academic Press.

Ward G. 1994. The RADIANCE Lighting Simulation and rendering system. Computer Graphics (Proceedings of \$iggraph 94).

Ward G. 1992. Radiance Visual Comfort Calculation.

sittp://radsite.lbl.gov/radiance/refer/Notes/glare.html> Accessed 2011 I0 Jan.

Wienold J, Cliristoffersen J. 2006. Evaluation methods and development of a new glare prediction modet for daylight environments with the use of CCD cameras. Energy and Buildings. 38(7): 743-757. 


\section{APPENDIX}

\section{Appendix Table 1. Summary of Phase I and Phase II test and reference conditions}

\begin{tabular}{|c|c|c|}
\hline 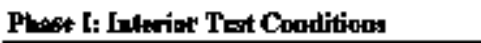 & Code & Daybiquhtin / Cactrol Strateg \\
\hline Andomased, splin opheal venettan bilind & anto-spitil-mir-VB & 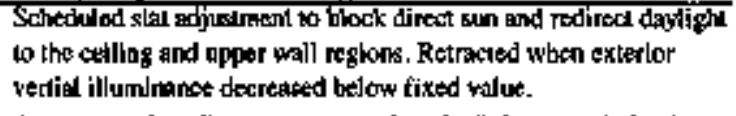 \\
\hline Alsonesiled, monle-whire ventian bind & ดงko-VB & 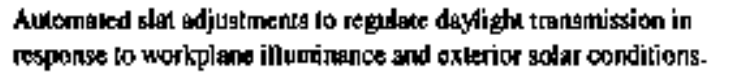 \\
\hline Manutally-operaked, optical ycnetian blind & splil-opt-VB & $\begin{array}{l}\text { Reflective slats wilh a prismatic fonctlon to redirect daylighl onto } \\
\text { lthe ceiling and upper wall regions. }\end{array}$ \\
\hline Manulatly-apented, split venetian blind & split-vB & $\begin{array}{l}\text { Semi-gloss white coeting on top surface of slals to diffugly neflect } \\
\text { incident daylight. Lower surface is brueded sliter with low.e }\end{array}$ \\
\hline $\begin{array}{l}\text { Automaled, flberglassipVC fabrle roller } \\
\text { shade }\end{array}$ & anto-RS & $\begin{array}{l}\text { Auromated heighl adjostments to limit dayllght penetration to a } \\
\text { depth of } 0.91 \text { of (3 fo from the interiot tace of glaylag. }\end{array}$ \\
\hline 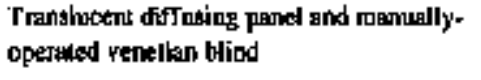 & diffuse.vs & 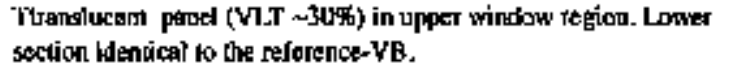 \\
\hline \multicolumn{3}{|l|}{ Phase II: Eiteriar Test Cootilitens } \\
\hline $\begin{array}{l}\text { Magnualiy-opernted, full beight venction } \\
\text { blind }\end{array}$ & VB-EIn & 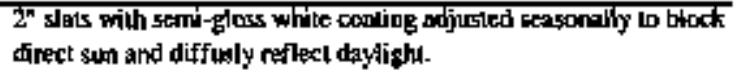 \\
\hline Aubsmated, Jull-foight ventitan blind & VE-Eln-andonl & 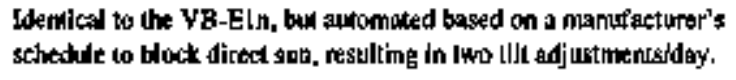 \\
\hline $\begin{array}{l}\text { Manually-eperated, full beight two-mone } \\
\text { venetlan blind }\end{array}$ & VE.E2n & $\begin{array}{l}\text { Zoned version of the VB-Elth. The uppert zone was set al a more } \\
\text { open posillon relative to the lower zone to increase daylight }\end{array}$ \\
\hline $\begin{array}{l}\text { Aunomated, full-height twa-zone venetlan } \\
\text { blind }\end{array}$ & VB-E2n-andon1 & 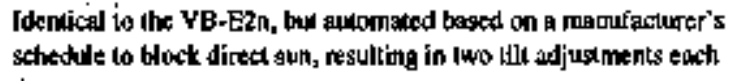 \\
\hline $\begin{array}{l}\text { Manually-operated, three-zone minored } \\
\text { horizonial louryer system }\end{array}$ & VE-ESapt & 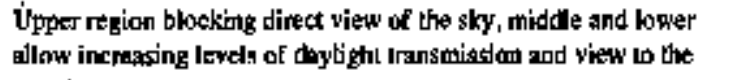 \\
\hline Automated, fabric moller shade & RS-E-aukd I & Fxlerior version at suba-RS. \\
\hline \multicolumn{3}{|l|}{ Aeforemese Conditians } \\
\hline \$ctasoneil]y-operaled interior vethetian Gind & Referente-VB & 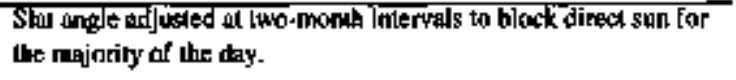 \\
\hline Static fahric roller shade & reference-RS & $\begin{array}{l}\text { Sed an a rixed height of } 0.76 \mathrm{~m} \text { (30 inch) above the floor for the } \\
\text { turadion of testing. }\end{array}$ \\
\hline
\end{tabular}


Appendix Table 2. Description of Venetian blind systems

\begin{tabular}{|c|c|c|c|c|c|c|c|c|c|}
\hline 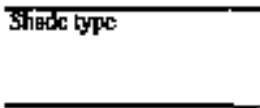 & Zone & $\begin{array}{l}\text { Syat } \\
\text { tancave }\end{array}$ & $\begin{array}{l}\text { Silt } \\
\text { molth } \\
\text { (mm) }\end{array}$ & $\begin{array}{r}\text { SIJM } \\
\text { Width } \\
\text { (1/a) }\end{array}$ & $\begin{array}{l}\text { Shat } \\
\text { specing } \\
\text { (inara) }\end{array}$ & $\begin{array}{r}\text { Stat } \\
\text { opacing } \\
\text { (10) }\end{array}$ & startep stortaces & SAl belkem surfice & $\begin{array}{l}\text { Depertioust } \\
\text { deus ginged }\end{array}$ \\
\hline \multicolumn{10}{|l|}{ lnierter System } \\
\hline 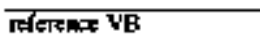 & nowe & down & 254 & 10 & 200 & 079 & semin glode phote & semu phoss whule & no \\
\hline \multirow[t]{2}{*}{ spt v8 } & यрम & benn & 230 & 10 & 200 & 679 & 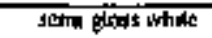 & folloctive metal & yas \\
\hline & Toner & down & 250 & T. & 2070 & $0 \times$ & whitc & Titlextre matel & yos \\
\hline \multirow[t]{2}{*}{ sphlil=opd-VB } & upper & 4 & 250 & 10 & 170 & 087 & malle whulc & ponstra & nó \\
\hline & Tomer & 4 & 250 & 10 & TIO & 067 & pitin & natre phot & $\overline{D O}$ \\
\hline \multirow[t]{2}{*}{ Bolr--日phi-mur-VB } & чірpct & $\mathbf{p p}$ & 825 & 32 & 714 & $2 \mathrm{BL}$ & Jamor & malk शpay & yes \\
\hline & loner & 甲 & $\overline{525}$ & 32 & 714 & $2 \mathrm{BI}$ & shurty uhudt & thine stay & $\overline{y e s}$ \\
\hline anlor-VB & bone & dom & 234 & T11 & 200 & $0 \%$ & ansulto whe & nedre white & $\overline{A O}$ \\
\hline ताf'V' & Tonet & doxn & 254 & To & 200 & $7 \%$ & 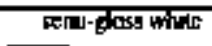 & ston-ghass whit & $\overline{\mathrm{ng}}$ \\
\hline \multicolumn{10}{|l|}{ Buterior S fotens: } \\
\hline 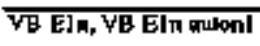 & nowe & domp & 1000 & 394 & 850 & 335 & 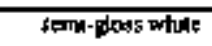 & 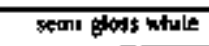 & $\overline{00}$ \\
\hline \multirow[t]{2}{*}{ 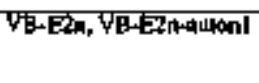 } & 1чppa & domn & 1000 & 394 & 85.0 & 33,5 & 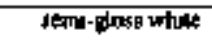 & 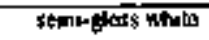 & $\overline{p o n}$ \\
\hline & Iower & domn & 1000 & 394 & 850 & 335 & tefln-phoss whate & setu-Ekins xhoto & $\overline{\mathbf{n}_{0}}$ \\
\hline \multirow[t]{3}{*}{ VB Ełopt } & uppg & down & $n \theta$ & 303 & 300 & 276 & polešted alumang & midic lartin stay & yest \\
\hline & moddlc & dom & $\pi 0^{\circ}$ & 303 & rovo & 276 & 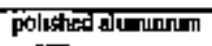 & 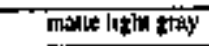 & yest \\
\hline & Toner & dentin & no & 303 & 300 & 276 & poluted alumulum & 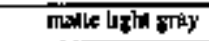 & yes \\
\hline
\end{tabular}


Appendix Table 3. Operation of Venetian blind systems

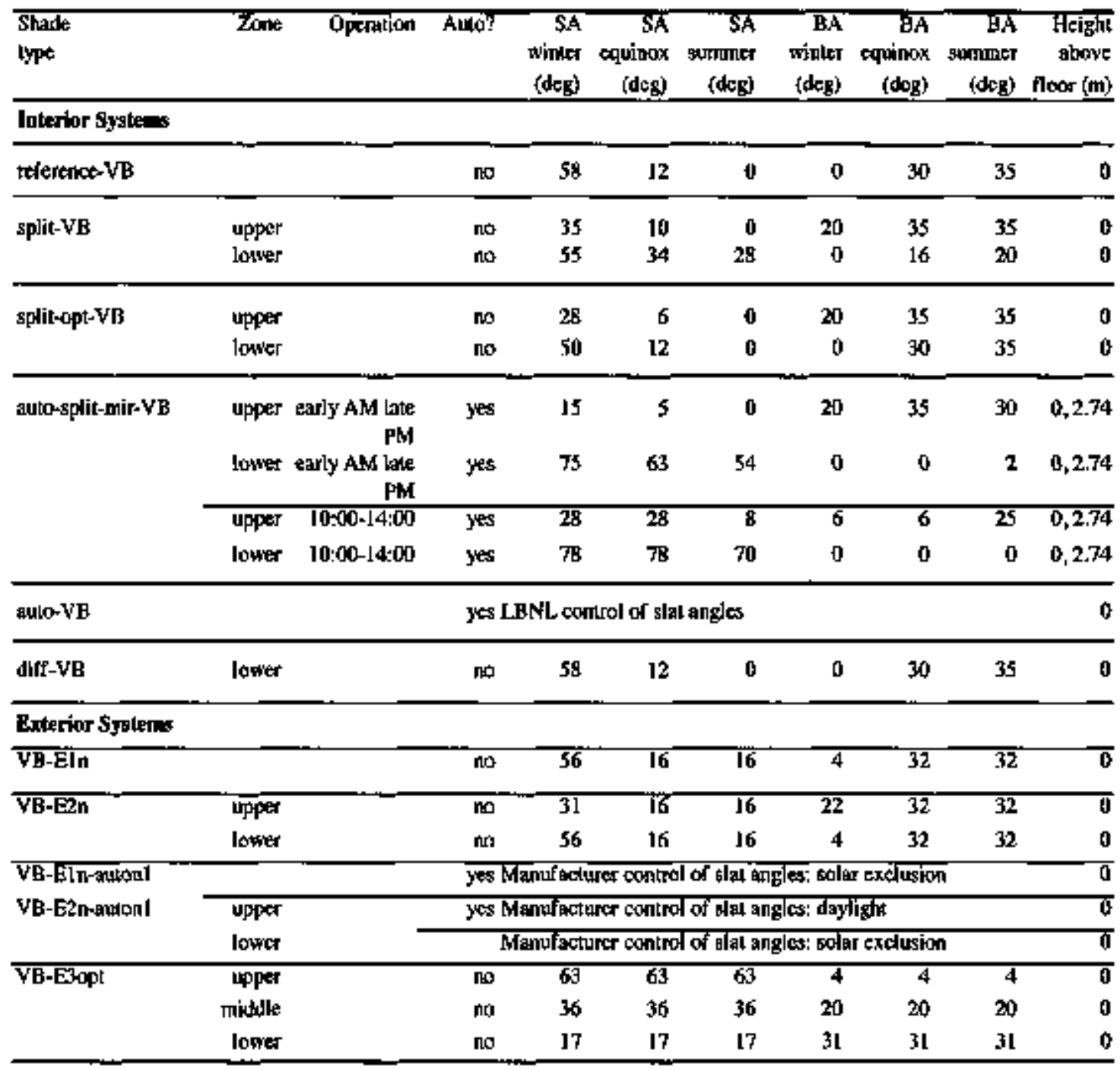

Positive slat angle: Occupsm can see the exicrior ground from the interior.

Auto: automaled; SA: slat angle; BS: blocking angle; deg: degres

Blocking angle is defined as the profile or cut-off angle belween two slats at normal incidence to the ghass.

Slat aagle was defined as the angle between horizonkal and the plane defined by the two onlside edges of the slat. 